\title{
El incrementalismo fiscal, una realidad evidente desde el Derecho económico ${ }^{1}$
}

\author{
JUAN CAMILO ROJAS ARIAS ${ }^{2}$
}

\section{RESUMEN}

Este trabajo consiste en recorrer la historia y estructura del sistema fiscal colombiano, bajo una perspectiva jurídica y económica, con miras a desentrañar su evolución y sus efectos en la realidad económica colombiana.

Palabras claves: Sistema tributario, Incrementalismo.

\section{FISCAL INCREMENTALISM, A REALITY EVIDENT FROM ECONOMIC LAW}

\section{ABSTRACT}

This work consists of traversing the history and structure of the Colombian tax system, from a juridical and economic perspective, with a view to unraveling its evolution and its effects on the Colombian economic reality.

Keywords: Tax System, Incrementalism.

1 Fecha de recepción: 5 de septiembre de 2017. Fecha de aceptación: 30 de mayo de 2018. Para citar el artículo: ROJAS ARIAS, J. C. (2018). El incrementalismo fiscal, una realidad evidente desde el Derecho económico en Revista Con-texto, n. ${ }^{\circ}$ 49, pp. 135-171. DOI: https://doi.org/10.18601/01236458.n49.07

2 Abogado egresado de la Universidad de La Sabana, candidato a doctor por la Universidad de Salamanca en España, con dos Maestrías en Derecho Internacional y en Análisis Económico del Derecho y de las Políticas Públicas y especialista en Derecho Comercial. Ha sido profesor de cátedra de la asignatura Fundamentos de Derecho Comercial y de la Empresa en la Universidad de La Sabana y Director del Semillero de Investigación en tratados comerciales. En el ámbito profesional, se ha desempeñado como Secretario General de inNpulsa Colombia, Director Jurídico de los patrimonios autónomos ProColombia y Fondo Nacional del Turismo - Fontur y asesor jurídico de los Ministerios de Hacienda y Crédito Público, Ministerio de Comercio, Industria y Turismo y del Ministerio de Relaciones Exteriores. Correo-e: camilor99@hotmail.com 
La bistoria es el filosema de nuestro sistema tributario

Es mejor cojear por el camino que avanzar a grandes pasos fuera de él, pues quien cojea en el camino, aunque avance poco, se acerca a la meta, mientras que quien va fuera de él, cuanto más corre, más se aleja.

SAN AGUSTÍN

\section{ESTRUCTURACIÓN Y COMPETITIVIDAD DEL SISTEMA TRIBUTARIO COLOMBIANO}

Para abarcar un entendimiento integral de la competitividad y estructura del sistema tributario en Colombia, es preciso incluir, de ser posible, todos los factores que han llevado al sistema tributario a lo que es hoy en día. Para este propósito, en el presente estudio se analizará el proceso de formación del sistema tributario desde sus orígenes, para así entender la razón de ser y estado actual del sistema. Posteriormente, se harán algunas reflexiones de índole jurídica y económica para, a la luz de indicadores internaciones, analizar un aspecto de la competitividad fiscal colombiana.

\section{La tributación, la economía y el sistema fiscal colombiano a través del tiempo}

Los sistemas fiscales, al igual que los seres humanos, son sistemas inacabados, imperfectos, llenos de propósitos y con una evidente necesidad desde su concepción de transformarse, de aprender y devenir algo diferente de sí mismo, siempre bajo la premisa de no distorsionar la realidad económica de terceros y en procura de generar efectos exógenos positivos sobre la sociedad. Si bien los sistemas fiscales no gozan de la benevolencia humana de aprender de sus errores, permitirlo es un concepto que va más allá de la renta individual de cada uno, es entrar en un proceso de distanciamiento severo de nuestro estado de naturaleza más primitivo para un entendimiento social más justo y equitativo. Al fin de cuentas los sistemas tributarios son como las personas, indefectiblemente son el producto de una coyuntura y una realidad específica e individual, que puede afectar su estructura, su ideología y a quienes le rodean, factores subjetivos que a través de la medición se pueden corregir eliminando todos los sesgos perversos innatos de su existencia acumulada y permitiendo que se llegue al tan quimérico concepto de competitividad en un mundo ya por hecho interconectado.

\section{a. Comienzos de un sistema tributario colombiano (siglos XIX-XX)}

El devenir en la construcción del Estado colombiano en lo relativo a los impuestos parte objetivamente desde el fin de la época del Virreinato de Nueva Granada (siglo XVIII), por parte del Virreinato español y el comienzo de la conformación del país emancipado conocido como las Provincias Unidas de la Nueva Granada. Para esta época, los tributos 
existentes eran principalmente de naturaleza directa, tales como (i) el tributo de los indios y (ii) las medias anatas seculares o eclesiásticas, e indirectos como los existentes sobre (i) la minería, (ii) la alcabala, (iii) los estancos y (iv) el monopolio sobre el tabaco, el aguardiente y la sal ${ }^{3}$, productos que afectaban directamente el producto interno. En virtud del surgente proceso de unificación, se detectó la necesidad de modernizar la fuente de ingresos públicos con miras a dar frente a las nuevas realidades del contexto y de la fuerte influencia de la época liderada por las corrientes inglesas de entender a los sistemas fiscales más allá de ser arcas de discrecionalidad soberana, sino como instrumentos sociales de equidad y de progreso económico ${ }^{4}$. En este sentido, recobró vital interés la idea de propiciar fuentes de ingresos para cubrir el creciente sostenimiento de una nueva administración pública y de los ejércitos de liberación liderados por Simón Bolívar ${ }^{5}$. Este clivaje social y político que alentó la modernización de instrumentos fiscales detectó la necesidad de gravar la riqueza individual de los ciudadanos de acuerdo con sus posibilidades, en contraposición al retiro de los impuestos indirectos que resultaban conforme a la infraestructura de la época y, en consonancia con las corrientes de pensamiento provenientes de Inglaterra, bastante costosos de administrar (recaudo) ${ }^{6}$.

Para el año de 1821, época en la cual se registró la primera República del Estado

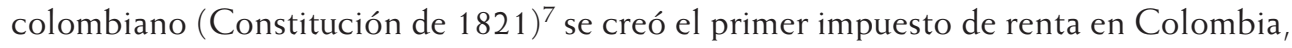
con una tarifa del $10 \%$ sobre lo producido por la tierra y el capital y en un rango entre el $2 \%$ y $3 \%$ sobre ingresos personales ${ }^{8}$ con una exención general sobre las personas cuyo patrimonios no ascendieran a más de $\$ 100$, prerrogativa ampliada en 1825 a $\$ 200^{[9]}$.

Hablar de administración pública y del establecimiento de un sistema tributario, inexorablemente, debe conllevar un análisis de los factores exógenos -políticos- en los cuales se desenvolvía la gestión pública de la época. Bajo este entender, se resalta que el gobierno de la época estaba regentado por SIMÓN BOLÍVAR y por FRANCISCO DE PAULA SANTANDER, líderes políticos marcados por una fuerte influencia del liberalismo francés y por el liberalismo inglés, sistemas que dejaron reconocibles sesgos ideológicos y bases dentro de la estructura administrativa de la época. En cuanto a la estructuración económica, se resalta la fuerte influencia utilitarista del filósofo y economista JEREMY BENTHAM

3 Restrepo, Juan Camilo, Hacienda Pública, Universidad Externado de Colombia, 2003.

4 Duverger, Maurice, Hacienda Pública, Barcelona: Bosch, 1968.

5 Pinto Bernal, José JoAquín, "Los orígenes del impuesto directo y progresivo en América Latina", Historia y Sociedad, 2012.

6 Pinto Bernal ,José JoAquín, "Los orígenes del impuesto directo y progresivo en América Latina" "como lo mencionó Adam Smith, los impuestos indirectos requerían una amplia cantidad de funcionarios para su recaudo, desalentaban la producción al incrementar los precios de las mercancías, estimulaban el contrabando y oprimían a los contribuyentes al ser víctimas de las constantes visitas e inspecciones de los encargados del fisco, Adam Smith, Investigación de la naturaleza y causas de la riqueza de las naciones, 773-776" Historia y Sociedad, 2012.

7 También conocida como la Constitución de Cúcuta o como la Constitución de la Gran Colombia.

8 LEWIN, Alfredo, "Historia de las reformas tributarias en Colombia", en autores varios, Fundamentos de la Tributación, Universidad de los Andes, Editorial Temis, 2008.

9 Bernal Pinto, José JoAquín, "Los orígenes del impuesto directo y progresivo en América Latina". Historia y Sociedad, 2012. 
como principio rector de la estructuración de un sistema social y político igualitario, enfocado en la incesante busca de la felicidad y del bienestar de la mayoría ${ }^{10}$, postulados que tuvieron gran acogida en estos periodos de guerra y conflicto y que fueron el germen del naciente sistema tributario colombiano.

Así las cosas, dentro del descrito proceso de estructuración de este nuevo Estado colombiano, surgieron conflictos internos que no permitieron una cabal implementación del nuevo sistema tributario, así como las constantes pugnas por el poder y la precaria capacidad administrativa de implementar un sistema tributario que pudiera hacer frente a las ideologías de la época dejaron de facto estipulaciones tributarias sin aplicación real ${ }^{11}$.

Posteriormente, deviene la desintegración del extinto Estado de la Gran Colombia ${ }^{12}$ por la divergencia política de quienes la conformaban, de la falta de representatividad en el sistema legislativo imperante y una inviabilidad fiscal de sostener esa gran estructura administrativa que suponía esa Gran Colombia ${ }^{13}$, lo cual se decantó en una época de grandes cambios políticos y administrativos que dieron lugar a la República de la Nueva Granada, luego con el federalismo de la Confederación Granadina - Estados Unidos de Colombia, lo cual devino finalmente en la República de Colombia, como se conoce hasta nuestros días ${ }^{14}$. Del trasiego legal y económico expuesto de vicisitudes y formación de Estado, no fue sino en la presidencia de MARCO FIDEL SuÁrEZ y el Ministro de Hacienda Pomponio GuZMán, en 1918, mediante la Ley 56, y el Decreto 794 de 1919, que se estructuró con efectos reales un impuesto directo en Colombia: el impuesto de renta. Este impuesto se estructuró sin cuidado de criterios de progresividad; a este efecto, para su tasación y recaudación, se segmentaron la base gravable y las tarifas en tres grupos, así: "(i) La renta que provenga únicamente del capital, que pagará el tres por ciento (3 por 100); (ii) La renta proveniente del capital combinado con la industria del hombre, que pagará el dos por ciento (2 por 100) anual, y (iii) La renta proveniente solo de la industria o del trabajo, que pagará el uno por ciento (1 por 100) anual. Del total de la renta de cada individuo, se deducirá la suma de trescientos sesenta pesos $(\$ 360)$ que no pagará impuesto"15, tarifas y operatividad deficientes que no permitieron a este impuesto cumplir su papel de instrumento eficaz de recaudo ni como herramienta de equidad, razón por la cual se modificó el impuesto de renta establecido en cuanto al alcance de la

10 Bravo, Carlos, "El pensamiento económico de Jeremy Bentham". Revista Ciencias Humanas. UTP, 2000.

11 LEWIN, Alfredo, "Historia de las reformas tributarias en Colombia", en autores varios, Fundamentos de la Tributación, Universidad de los Andes, Editorial Temis, 2008.

12 La Gran Colombia estaba conformada por la Capitanía General de Venezuela, la Presidencia de Quito, La Provincia Libre de Guayaquil y el Virreinato de la Nueva Granada, que actualmente, en territorio, corresponde a lo que conocemos como Colombia, Ecuador, Venezuela y Panamá.

13 Pinto Bernal, José JoAquín, "Las Finanzas de la Gran Colombia". Instituto de Estudios Latinoamericanos, Universidad de Alcalá, 2012.

14 Jaramillo Uribe, Jaime, Etapas y Sentido de la Historia de Colombia (Periodo Colonial, La Gran Colombia 1820-1830, La República de Nueva Granada 1830-1850, Las Reformas liberales de 1850, El Federalismo). Banco de la República, Biblioteca Virtual. http://www.banrepcultural.org/blaavirtual/historia/colhoy/colo4.htm.

15 Ley 56 de 1918 del 27 de noviembre. Diario Oficial 16.555. 
base gravable, eliminando el origen de la fuente de la riqueza como elemento determinante de la tarifa ${ }^{16}$. Así, también, introdujo los conceptos de renta líquida, renta bruta y deducciones ${ }^{17}$, y estableció un sistema claro de progresividad al asignar la tarifa del impuesto según la renta de las personas en un rango entre el 1\% y el $8 \%$ para las rentas líquidas más altas, e impuestos a las personas jurídicas. En virtud de los esfuerzos de la época por generar un sistema tributario progresivo a través del establecimiento de impuestos directos y supresión de impuestos indirectos de conformidad con que estos últimos, según las ideologías de este tiempo, promovían sociedades socialistas y regímenes inescrupulosos ${ }^{18}$, se concibió la Ley 78 de 1935, que introdujo 2 nuevos impuestos directos a este incipiente sistema tributario colombiano, el impuesto al patrimonio ${ }^{19} \mathrm{y}$ al exceso de utilidades ${ }^{20}$, bajo argumentos de equidad y eficacia administrativa, toda vez

16 Ley 64 de 1927 del 12 de noviembre. Diario Oficial 20.684. Artículo $3^{\circ}$ Establécese un impuesto sobre todo individuo residente en Colombia, que será tasado, exigido, recaudado y pagado anualmente con relación a su renta total líquida, como aquí se define, correspondiente al año civil anterior, según la siguiente tarifa (...).

17 Ley 64 de 1927 del 12 de noviembre. Diario Oficial 20.684. Artículo 1: Renta líquida es la renta bruta del contribuyente, menos las deducciones concedidas por esta Ley. La renta bruta comprende ganancias, beneficios y rentas provenientes de salarios, jornales o compensaciones por servicios personales de cualquier clase y en cualquier forma que se paguen, o de profesiones, negocios comerciales, lo mismo de intereses, arrendamientos, dividendos, seguridades o transacciones de negocios llevados a cabo con objeto de lucro, con inclusión de ganancias, beneficios o rentas provenientes de sucesiones o fideicomisos recibidos por los respectivos beneficiarios, ya sea en cuotas distribuidas o por distribuir. El monto de tales cantidades será incluido en la renta bruta correspondiente al año gravable en que sea recibida por el contribuyente o fideicomisario.

18 LEWIN, Alfredo, "Historia de las reformas tributarias en Colombia", en autores varios Fundamentos de la Tributación, "en cita de la obra Memoria de Hacienda "El impuesto indirecto, por la forma disimulada, o mejor dicho, por la facilidad con la que se difunde o transfiere a otras personas en el trafico económico privado, vuelve egoísta al ciudadano y le bace concebir una noción exagerada de su derecho individual. Por eso los Estados antiguos fueron individualistas fanáticos. Y por eso en Colombia, en donde el impuesto indirecto ba sido en todo tiempo, basta abora, la principal fuente de entradas fiscales, el individualismo rígido crece como planta espontanea, no solamente dentro de los partidos de tradición, sino también dentro de los partidos avanzados. Esteban Jaramillo, Memoria de Hacienda 1935-1936, Bogotá Editorial Nueva. pp. 33" Universidad de los Andes, Editorial Temis, 2008.

19 Ley 78 de 1935 del 13 de diciembre. Diario Oficial 1936. Artículo 21. Establécese un impuesto anual sobre el patrimonio poseído dentro del país, en 31 de diciembre del año anterior, por toda persona natural o jurídica, nacional o extranjera, sujeta al impuesto sobre la renta en Colombia, impuesto que se tasará mediante declaraciones juradas de los contribuyentes, en una misma diligencia, con ocasión de la tasación, exigencia y recaudación del impuesto sobre la renta, y de acuerdo con la reglamentación que al efecto dicte el poder ejecutivo.

En consecuencia, y para todos los efectos legales, el impuesto sobre la renta, el adicional sobre utilidades y el complementario sobre el patrimonio, se considerarán como un todo indivisible.

Es entendido que las personas que no tengan renta gravable, pero si posean patrimonio, deben pagar la tasa adicional que esta Ley establece.

Para los efectos de esta Ley, se denomina patrimonio el conjunto de derechos apreciables en dinero que tiene una persona, deducido el monto de sus deudas.

20 Ley 78 de 1935 del 13 de diciembre. Diario Oficial 1936. Artículo 13. Establécese un impuesto adicional al de la renta, sobre el exceso de utilidades líquidas, obtenidas en cada año gravable por las personas naturales o jurídicas gravadas con impuesto sobre la renta en Colombia. 
que se dedujo que las rentas de capital debían gravarse más alto que las de trabajo y se establece un parámetro de fiscalización rupestre al determinar la renta por la variación del patrimonio por años ${ }^{21}$. Bajo esta misma tendencia, la Ley 63 de 1936 creó los impuestos sobre las herencias $^{22}$, y las asignaciones y donaciones ${ }^{23}$.

Pasado este tiempo, resulta relevante enfocar la atención en el periodo de guerra mundial (1941), marcado por ciclos de decrecimiento económico y de presión fiscal, principalmente sobre el mercado cafetero, que, como efecto directo, tuvo una repercusión negativa por el decaimiento general de las exportaciones en un $5 \%{ }^{24}$, lo que incentivó una serie de medidas tributarias tales como la eliminación de los gravámenes de los giros, la prórroga de determinados impuestos ${ }^{25}$, una sobretasa al impuesto de renta mediante las Leyes 45 de 1942 y 35 de 1944, y la creación de nuevos impuestos, tales como el de la retención para financiar las cuotas cafeteras y las deudas del tesoro ${ }^{26}$.

Después de este periodo de recesión, se generó un proceso expansionista de la economía colombiana, con un crecimiento del PIB a una tasa real del 4,3\% ${ }^{27}$, producto de una marcada explotación del café, que para la época representaba el 70\% de las exportaciones de Colombia, lo que permite ver una marcada dependencia de este producto, razón que fundamentó políticas de estímulo industrial diferentes del café con el objetivo de reemplazar las importaciones con producción nacional, por lo cual se realizó la reforma tributaria de 1953, la cual tuvo un fuerte impacto en la estructura tributaria colombiana, a través del propósito de incrementar el recaudo, incentivar la producción nacional y garantizar una distribución de la riqueza más equitativa. Para este fin, se acrecentaron los aranceles -medida proteccionista- y se creó un impuesto dual de renta para las sociedades y $\operatorname{los} \operatorname{socios}^{28}$. Para finales de este ciclo se pretendió, motivado por la Junta Militar que ostentaba el poder después de la renuncia del General Rojas Pinilla para ser presentada

Entiéndese por utilidades líquidas la diferencia entre la renta bruta y las deducciones y exenciones otorgadas por la Ley 81 de 1931, modificada por la presente.

21 LEWIN, ALFREDO, "Historia de las reformas tributarias en Colombia", en autores varios Fundamentos de la Tributación, Universidad de los Andes, Editorial Temis, 2008.

22 Ley 63 de 1936 del 23 de abril. Diario Oficial 23.165. Artículo 1. Establécese un impuesto progresivo sobre las sucesiones, impuesto que se hará efectivo sobre el monto líquido de la masa global hereditaria, que, para los efectos de esta Ley, consiste en la totalidad del activo dejado por el difunto o causante, previas las acumulaciones y deducciones de que más adelante se hablará.

No está sujeto al impuesto lo que recoja por gananciales el cónyuge sobreviviente.

23 Ley 63 de 1936 del 23 de abril. Diario Oficial 23.165. Capitulo II Artículo 11 y subsiguientes.

24 Junguito, Roberto ; Rincón, Hernán, "La Política Fiscal en el Siglo XX en Colombia", documento preparado para el seminario "Investigaciones recientes sobre historia económica colombiana", 2004. Disponible en https://core.ac.uk/download/files/153/7077619.pdf.

25 Impuestos de Defensa Nacional.

26 LEWIN, AlFREDO, "Historia de las reformas tributarias en Colombia", en autores varios Fundamentos de la Tributación, Universidad de los Andes, Editorial Temis, 2008

27 Junguito, Roberto; Rincón, Hernán, "La Política Fiscal en el Siglo Xx en Colombia", documento preparado para el seminario "Investigaciones recientes sobre historia económica colombiana", 2004. Disponible en https://core.ac.uk/download/files/153/7077619.pdf. 
al Congreso, una nueva reforma tributaria con el propósito innovador de constituir una comisión de expertos para que se desarrollara un solo documento compilatorio que contuviera de manera sistemática y ordenada todas las normas que sobre naturaleza tributaria estuvieren vigentes para la época. Bajo este marco, se constituyó la reforma tributaria de 1960, mediante la Ley 81 de 1960.

La anotada reforma marcó un hito dentro del sistema fiscal colombiano, toda vez que no solo acuñó la dispersión de normas en estas materias, sino que replanteó el impuesto nacional sobre la renta, incorporó nuevas bases de gravamen, se le dio un nuevo alcance a los complementarios del patrimonio y el exceso de utilidades, además de la incorporación de normas antielusión, todo esto sobre una base de intervención pública para la equidad y la eficiencia, a través de la justa distribución del ingreso nacional mediante el desmonte de determinados impuestos sobre las personas ${ }^{29}$, tales como las rentas pequeñas y medianas, esencialmente las de trabajo, así como una profunda revisión sobre los impuestos a las sociedades y un ambicioso régimen de incentivos a la producción nacional, todo bajo una estricta observancia de no generar distorsiones en los mercados ni en el plano social ${ }^{30}$. En este sentido, se procuró "dirigir la tributación en forma que sirviera de incentivo a la producción nacional, especialmente en renglones que disminuyeran las importaciones o aumentaran las exportaciones para fortalecer la decaída balanza de pagos" 31 .

No obstante los buenos propósitos y la acuciosidad que ostentó su aprobación legislativa $^{32}$, la reforma de 1960 no arrojó los resultados esperados en eficacia, eficiencia y equidad, de acuerdo con la situación macroeconómica de la época. La aludida reforma contribuyó a un debilitamiento de los ingresos públicos, lo que llevó a una situación de déficit presupuestario, toda vez que el desmonte de los impuestos, después del trámite legislativo, resultó más amplio que lo proyectado, compaginado al déficit fiscal generado por el gasto público, que se encontraba en un ciclo creciente. Sobre este particular, se estimó que los gastos del sector público se encontraban en un ciclo ascendente de 1,1 puntos del producto interno bruto entre 1960 y $1962^{[33]}$. Todo esto permitió afirmar que la reforma de 1960 fue un descalabro en la fiscalidad colombiana, generando de facto

RODRíGUEZ, ÓSCAR, "Nuevas perspectivas en Historiografía Fiscal". Cuadernos de Economía, V. XV n. ${ }^{\circ} 24$, 1996.

30 LEWIN, Alfredo, "Historia de las reformas tributarias en Colombia", en autores varios Fundamentos de la Tributación, Universidad de los Andes, Editorial Temis, 2008.

31 Escuela Superior de Administración Pública, ESAP. 1961-62. La reforma Tributaria de 1960, 1961.

32 Lewin, Alfredo, "Historia de las reformas tributarias en Colombia", en autores varios Fundamentos de la Tributación "La Ley 81 de 1960 indudablemente estuvo inspirada en las concepciones cepalinas de moda en aquella época. Los incentivos que se propusieron en el proyecto de Ley se ampliaron y las tarifas se redujeron con motivo de la discusión en el Congreso. Esta reforma fue reglamentada mediante el Decreto 437 de 1961 y en ejercicio de facultades extraordinarias otorgadas por la Ley 81 de 1960, se dictó un estatuto de procedimiento mediante el decreto 1651 de 1961 ". Universidad de los Andes, Editorial Temis, 2008.

33 Junguito, Roberto; Rincón, Hernán, "La Política Fiscal en el Siglo Xx en Colombia", documento preparado para el seminario "Investigaciones recientes sobre historia económica colombiana", 2004. Disponible en https://core.ac.uk/download/files/153/7077619.pdf. 
un sistema regresivo y una pérdida progresiva de recaudo de un punto porcentual del producto interno bruto de la época ${ }^{34}$.

La descrita situación de presión fiscal terminó por decantarse en una nueva ley fiscal con fines recaudatorios, la Ley 21 de $1963^{[35]}$, que revistió al presidente de facultades excepcionales a fin de hacer frente a la coyuntura económica, así:

[...] De conformidad con el artículo 76, ordinal 12, de la Constitución Nacional, y a fin de buscar una adecuada estabilidad fiscal, económica y social ${ }_{i}$ de proveer los recursos necesarios para la ejecución del Plan de Desarrollo Económico y Social y de reducir los gastos de funcionamiento de las entidades y dependencias nacionales, (...), revístese al Presidente de la República de facultades extraordinarias por el término de que trata el parágrafo 2o. de este artículo para: $[\ldots]$

Tercero.- Dictar normas en materia tributaria, a fin de simplificar, ordenar y agilizar la liquidación, registro y control de los impuestos, sin eliminar los recursos de que actualmente gozan los contribuyentes. En relación con los recaudos el Gobierno podrá aumentar los Juzgados de Ejecuciones Fiscales, establecer sistemas de percepción en la fuente, hacer obligatoria la liquidación privada y estatuir normas que faciliten el pago de los impuestos de sucesiones y donaciones.

Cuarto. Reformar y adicionar la legislación vigente en materia de avalúo de intangibles y sobre tarifas aplicables a sociedades que no repartan utilidades en el país [...]. (Destacado fuera de texto)

Por esta vía, en su momento, se determinó que el Estado colombiano disponía de una estructura tributaria de impuestos directos, conformados por la triada de impuesto de renta, exceso de utilidades y patrimonio, que era importante mantener y reforzar ${ }^{36}$. Siendo esto así, el gobierno nacional estableció por primera vez en su fiscalidad un impuesto a las ventas ${ }^{37}$ con tarifas que oscilaban entre el $3 \%$ y el $10 \%$, exceptuando determinados bienes de importancia social ${ }^{38}$. Así mismo, se fijó una sobretasa decreciente sobre el

34 Cárdenas, Mauricio; Perry, Guillermo, Diez años de reformas tributarias, Bogotá, Cid - Fedesarrollo, 1986.

35 Ley 21 de 1963 del 20 de agosto. Diario oficial 31.177 de 10 de septiembre de 1963.

36 Junguito, Roberto; Rincón, Hernán, "La Política Fiscal en el Siglo Xx en Colombia", documento preparado para el seminario "Investigaciones recientes sobre historia económica colombiana", 2004. Disponible en https://core.ac.uk/download/files/153/7077619.pdf.

37 Cabe anotar al margen que entre los años 50 y 70 el sistema tributario colombiano era característico de impuestos directos, situación que se fue desvirtuando con las modificaciones de la década del 60 relativas la creación del impuesto a las ventas, con lo cual los impuestos indirectos empezaron a cobrar gran importancia como fuente de recaudo nacional.

38 Ley 21 de 1963, Artículo Sexto. Establecer impuestos nacionales sobre las ventas de artículos terminados que efectúen los productores o importadores. Estos impuestos se harán efectivos a tarifas que fluctúen 
impuesto de renta entre el 20,1\% y el 5\% para los periodos comprendidos entre 1963 y 1965, y aumentó en un 30\% la tarifa de los impuestos sobre la masa global hereditaria.

Posteriormente, en el año de 1967, se dictaron sendas normas sobre evasión fiscal, tales como: el Decreto Ley 1366 de 1967 y la Ley 63 del mismo año, las cuales contenían disposiciones sobre repatriación de capitales, control a las utilidades en enajenación de activos, impuesto a la gasolina, el sistema de retención en la fuente sobre los ingresos, la no deducibilidad de ingresos vitalicios y límites a las deducciones. Así mismo, se incorporaron en la Ley 63 cuestiones relativas a la deducibilidad del pago de pensiones y de reparaciones locativas, se limitó el pago en los intereses de vivienda y se establecieron dos amnistías sobre la mora en el pago de impuestos y sobre pasivos no incluidos en declaraciones ${ }^{39}$. Aunque fue notoria la mejora en términos de ingreso y en el entendido de que la economía colombiana marchaba bien, se hizo evidente un desbalance entre la creciente economía y el decreciente recaudo fiscal ${ }^{40}$ situación que ayudó a cimentar el sistema de retenciones en la fuente mediante las Leyes 5 y 6 de 1973 . No obstante, estas medidas, aunque configuraron remedios temporales para el desbalance fiscal, ${ }^{41}$ no resultaron ser una respuesta sólida para la necesidad estructural en términos fiscales que se estaba gestando para la época.

Dentro del marco de asimetría evidenciado entre la situación económica y el recaudo fiscal, para 1974, la administración de Alfonso López Michelsen se decantó por una nueva reforma tributaria con un enfoque diferenciador del establecido en las pasadas reformas, que se concentraban en la inversión privada y en la visión del sistema tributario como un cúmulo de incentivos para la misma. Para esta ocasión, la teleología de esta nueva reforma se centraba en principios de equidad y recaudo, además de reconocer diferentes variables de la inversión privada para activar la demanda agregada, tales como el gasto público y la inversión social ${ }^{42}$. Bajo el enfoque expuesto, la reforma tributaria de 1974 implementada en el curso legal colombiano mediante un decreto de emergencia económica, trajo consigo profundas modificaciones fiscales y monetarias: se estableció el régimen de renta presuntiva, se crearon correctivos parciales para la inflación, se amplió el régimen de depreciación en porcentaje (hasta un 100\%) y en forma (formas aceleradas

entre el 3\% y el 10\%. Quedan exceptuados los artículos alimenticios de consumo popular, los textos escolares, las drogas y los artículos que se exporten.

39 LeWIN, Alfredo, "Historia de las reformas tributarias en Colombia", en autores varios Fundamentos de la Tributación, Universidad de los Andes, Editorial Temis, 2008.

40 Junguito, Roberto; Rincón, Hernán, "La Política Fiscal en el Siglo XX en Colombia", documento preparado para el seminario "Investigaciones recientes sobre historia económica colombiana", 2004. Disponible en https://core.ac.uk/download/files/153/7077619.pdf.

41 Para este fin, se realizó la Misión Musgrave en 1971, la cual hizo palpable el desbalance fiscal reinante para la época, informe que dejo entrever un impuesto de renta absolutamente distorsionante, encontrándose un $60 \%$ por encima de impuestos similares en el contexto latinoamericano y unos impuestos indirectos que se encontraban en un $50 \%$ por debajo de impuestos similares en la región latinoamericana, con lo cual se recomendó un fortalecimiento de los impuestos indirectos que, aunque resultaban en un recaudo más eficaz, no tenían la misma bondad en términos distributivos.

42 Cárdenas, Mauricio; Perry Guillermo, Diez años de reformas tributarias, Bogotá. Cid Fedesarrollo, 1986. 
de depreciación en el tiempo por uso excesivo); también se unificó el tratamiento tributario de las sociedades, distinguiendo únicamente entre empresas anónimas y asimiladas, con tarifas únicas para cada uno de estos grupos de $40 \%$ y $20 \%$. Se extendió el impuesto de renta a las empresas estatales, respectivamente, y se mantuvieron algunos de los beneficios de la Ley 81 de $1960^{[43]}$ y, conforme la recomendación de la Misión Musgrave, se fortaleció el sistema de impuestos indirectos. Para este fin, se elevaron las tarifas del impuesto a las ventas, se reclasificaron los bienes objeto de este gravamen, se estableció la gradualidad de las tarifas y se perfeccionó el sistema de descuentos y devoluciones en este sistema indirecto ${ }^{44}$.

Lastimosamente, la historia fue haciendo evidente el bucle de la regulación tributaria colombiana, toda vez que, en esta ocasión, como ha sucedido en diversas y anteriores oportunidades, la aludida reforma tributaria del 74 no resultó ser la herramienta óptima para conjurar el proceso inflacionario que se vivía en la época ni persuadir de una forma eficiente los sesgos individuales de los contribuyentes de evadir su responsabilidad fiscal. Además, una serie de reformas posteriores a la del 74 terminaron por cercenar las buenas intenciones fiscales plasmadas en esta, como por ejemplo: las introducidas por las Leyes 54 de 1977 y 20 de $1979^{[45]}$, por las cuales se redujeron la tarifas del impuesto de renta, con el fin de alivianar cargas a los ciudadanos en virtud del proceso inflacionario de los últimos años, se establecieron amnistías y se redujo el alcance de los impuestos a las ganancias ocasionales, con lo cual se produjo un contrasentido fiscal al terminar anulando el esfuerzo de la reforma de 1974, con lo cual, nuevamente, el Estado colombiano entró en un periodo de caída de los ingresos tributarios del 9\% al 6,8\% del PIB entre 1980 y 1984. Es de resaltar que en el periodo de 1978 a 1982, la visión fiscal de la época estuvo aparejada con un aparente y vigoroso crecimiento económico; entre 1978 y 1980, se tuvo un incremento en la producción nacional de 7,5\% anual, así como de la construcción, la agricultura, las ventas, el pleno empleo; en suma, la demanda agregada estaba en la senda de alcanzar su potencial, además de contar con una política monetaria eficaz con resultados eficientes, lo que se reflejó en una disminución de la tasa de interés y un alza generalizada en los salarios. No obstante, fue un momento expansionista momentáneo y el optimismo con el que se visualizaba la economía pronto se derrumbó por la inminente crisis económica internacional que se empezaba a sentir por entonces en Colombia. Para el año de 1982, las proyecciones económicas ya se registraban contraídas, pudiéndose apreciar el inicio de un nuevo ciclo recesivo para la economía colombiana debido a la caída del producto interno bruto, situación que justificó el empleo de una política contracíclica sin sacrificar el nivel de precios ni la inversión social ${ }^{46}$.

43 Departamento Nacional de Planeación. Las reformas tributarias en el siglo XX. Colombia. Giro Editores. 2002.

44 Ibíd.

45 Esta Ley reformó el impuesto a las ganancias ocasionales en su estructura de cálculo a través de la reducción de las tarifas del 46\% al 28\%. Así mismo, eliminó la provisión de que las ganancias ocasionales fuesen gravadas al 50\% de la tasa de impuesto a la renta. Ley 20 de 1979, Capitulo II - Ganancias Ocasionales. 
El marco fiscal inestable del momento, en el cual el recaudo decrecía y el gasto aumentaba, aunado a un entorno económico internacional adverso en el cual se combinó una caída generalizada de la producción mundial y unas tasas de interés elevadas, fue el que recibió posteriormente la administración del expresidente Belisario Betancur ${ }^{47}$, en la cual se detectó la necesidad de fortalecer el recaudo tributario y de incorporar una serie de disposiciones que evitaran las prácticas evasivas. Siendo este el objetivo, mediante un decreto de emergencia económica materializado en las Leyes 9 y 14 de 1983, se buscó dar un marco de refuerzo tributario tanto a nivel nacional como a nivel descentralizado. Para este fin, la Ley 9 de 1983 estableció una adición al impuesto de renta del 49\% de la renta líquida gravable, que superase determinado umbral de ingresos ${ }^{48}$. En igual sentido, se fortaleció el sistema antievasión y se extendió el régimen de renta presuntiva para las sociedades limitadas o asimiladas, se eliminó la doble tributación de las sociedades anónimas y se creó la presunción legal según la cual la renta líquida no podía ser inferior al $2 \%$ de los ingresos, y se establecieron estímulos sobre las actividades societarias sobre la capitalización y el reparto de utilidades. Por su parte, la Ley 14 del 83 se centró en el fortalecimiento de la tributación de los entes territoriales.

Finalmente, es de resaltar que el impuesto a las ventas terminó por decantarse en el impuesto que actualmente conocemos como de valor agregado (IVA), el cual se estructuró en amplia libertad por parte de la administración conforme la autorización impartida por el Congreso, estableciéndose con una tarifa del 10\% general, a excepción de determinados productos de características suntuarias especiales. Cabe agregar que la única restricción establecida fue la de no gravar bienes exentos ni superar el tope de tarifas fijado en un $35 \%{ }^{49}$.

Se hace evidente que la serie de medidas adoptadas por la administración y avaladas por el Congreso buscaban dar un renovado impulso a la economía en todos los niveles, fortaleciendo el régimen de ingresos tributarios regionales, estableciendo estímulos a las sociedades y reduciendo cargas impositivas provenientes de la doble tributación.

Aunado al marco fiscal y monetario resaltado, se realizaron nuevas reformas propulsoras para la economía. Bajo estos propósitos expansivos, a través de los incentivos fiscales, se tramitó la Ley 48 de $1983^{[50]}$ mediante la cual se creó el Certificado de Reembolso Tributario (CERT) ${ }^{51}$ con el fin de impulsar el sector industrial colombiano a través

preparado para el seminario "Investigaciones recientes sobre historia económica colombiana", 2004. Disponible en https://core.ac.uk/download/files/153/7077619.pdf.

47 Ibíd.

48 Ley 9 de 1983, Diario Oficial 36.274 de 15 de junio de 1983, Artículo 1.

49 LEWIN, Alfredo, "Historia de las reformas tributarias en Colombia", en autores varios Fundamentos de la Tributación, Universidad de los Andes, Editorial Temis, 2008.

50 Ley 48 de 1983 del 20 de diciembre de 1983, publicada en el Diario Oficial 36.421 del 27 de diciembre de 1983 - Por la cual se expiden normas generales a las cuales debe sujetarse el Gobierno Nacional para regular aspectos del comercio exterior colombiano.

51 Ley 48 de 1983, artículo 2. Del Certificado De Reembolso Tributario. Créase el Certificado de Reembolso Tributario, CERT, y elimínase el Certificado de Abono Tributario, CAT.

El Gobierno Nacional contratará con el Banco de la República la expedición y entrega de Certificados 
de la promoción de las exportaciones usando el mecanismo de devolución de impuestos indirectos pagados por los exportadores ${ }^{52}$.

Complementariamente, estas reformas fiscales se acompañaron de la política presupuestaria. Para 1985, se detectó la imposibilidad de continuar en la senda de gasto creciente que se venía por parte de la administración, lo cual debía ajustarse a las medidas de tipo fiscal elaboradas. Bajo este entender, y como política de control de gasto, el gobierno colombiano ajustó negativamente los salarios de los servidores públicos un $10 \%$ por debajo del índice de precios de ese momento. De igual forma, se redujo el gasto de inversión del 7,6\% del producto interno bruto a 5,9\% para 1986; con todo lo anterior aunado de la política fiscal se logró reducir el déficit acumulado de 5,5\% al 1,1\% respecto del producto interno bruto ${ }^{53}$.

Sumado a los esfuerzos expuestos, en 1986 se tramitó la Ley $75^{[54]}$, mediante la cual se introdujeron en el ya secuencialmente modificado sistema tributario colombiano una serie de reformas sobre el sistema de impuestos directos. Al efecto, se redujo la tasa máxima de renta sobre personas naturales al 35\%, así como se estableció un régimen de exención general sobre las personas asalariadas relativo al 90\%, se unificó el régimen impositivo de sociedades para efectos tributarios ${ }^{55}$ y se innovó en diversos frentes, así: en cuanto a la recaudación, se abrió la posibilidad de realizarla a través del sistema financiero; en cuanto al régimen de exención, se establecieron correctivos generalizados por inflación;

de Reembolso Tributario, CERT, a los exportadores, en las condiciones previstas en esta ley y en los decretos que la desarrollen.

PARÁGRAFO $1^{\circ}$. Para los efectos de esta ley, el Gobierno Nacional determinará quiénes se consideran exportadores.

52 Ley 48 de 1983, Artículo 3 del Certificado de Reembolso Tributario, CERT, como instrumento de apoyo a las exportaciones. El Certificado de Reembolso Tributario, CERT, será un instrumento flexible de apoyo a las exportaciones cuyos niveles fijará el Gobierno Nacional en cualquier momento de acuerdo con los productos, y a las condiciones de los mercados a los que se exporten. El Gobierno regulará la utilización del certificado consultando la realidad del comercio exterior, con el propósito de estimular la producción de bienes y servicios.

PARÁGRAFO $1^{\circ}$. En casos debidamente justificados el Gobierno podrá garantizar el mantenimiento de niveles del CERT durante un periodo determinado mediante celebración de contratos de exportación con personas naturales y jurídicas. Los contratos se celebrarán con el Instituto Colombiano de Comercio Exterior o con la entidad que haga sus veces, y se regirá por las disposiciones del Código de Comercio. PARÁGRAFO $2^{\circ}$. El Gobierno para otorgar el Certificado de Reembolso Tributario, CERT, a las exportaciones de servicios, deberá estructurar previamente mecanismos administrativos y sistemas de control que eviten fraudes e irregularidades, todo con el propósito de asegurar el cumplimiento de los objetivos que se persiguen con la creación del CERT.

53 Junguito, Roberto; Rincón Hernán, "La Política Fiscal en el Siglo Xx en Colombia", documento preparado para el seminario "Investigaciones recientes sobre historia económica colombiana", 2004. Disponible en https://core.ac.uk/download/files/153/7077619.pdf.

54 Ley 75 de 1986 del 24 de diciembre de 1986, publicada en el Diario Oficial 37.742.

55 Ley 75 de 1986, Artículo $1^{\circ}$. Fíjase en un treinta por ciento (30\%) la tarifa única sobre la renta gravable y las ganancias ocasionales de las sociedades anónimas, de las sociedades limitadas y de los demás entes asimilados a unas y otras de conformidad con las normas pertinentes. La misma tarifa se aplicará a la renta gravable y las ganancias ocasiones y a cualesquiera otras entidades extranjeras. 
en consecuencia, se incorporaron exenciones parciales sobre los rendimientos financieros correlativo a la inflación del momento, con el propósito de alivianar cargas inflacionarias producto de los últimos años en Colombia. Por su parte, eliminó el régimen de doble tributación interna al integrar la tributación de la sociedad y de los socios en cabeza de la sociedad, de tal suerte que el gravamen sobre utilidades retenidas como repartidas se radicó exclusivamente en cabeza de la sociedad. Finalmente, sobra advertir las diversas interpretaciones sobre los efectos de la anotada reforma en los sectores académicos de Colombia, siendo estos disimiles e inconexos; solo se resalta que, por una parte, de la academia se reconocen los efectos positivos sobre el recaudo y la simplificación tributaria que significó esta reforma ${ }^{56}$, en sentido contrario, se calificó esta misma reforma como una persistencia inadecuada de concepciones "de manera que la debilidad en la administración persistió, y la neutralidad, equidad y el potencial del recaudo se vieron seriamente afectados" (PERRY, 1988) ${ }^{57}$.

\section{b. Finales del siglo XX y comienzos del siglo XXI}

Para 1991, se da el clivaje jurídico y económico más importante de Colombia en los últimos años, relativo a la instauración de un nuevo marco de realidad jurídica ${ }^{58}$, política y económica, este nuevo escenario sucede con la promulgación de la Constitución de 1991, mediante la cual el Estado colombiano se organizó como estado social de derecho, con bases democráticas afirmadas en la más alta dignidad jurídica, como política exterior se instauró la apertura económica y la confianza en el funcionamiento de los mercados, teniéndose como supuesto subyacente que la iniciativa privada es el elemento determinante del crecimiento económico ${ }^{59}$, estructura económica muy acorde con las demás economías de la región. No obstante, el éxito económico vivido en esta nueva etapa no fue el resultado mágico e instantáneo de un proceso de apertura, sino resultado del continuado programa económico que se venía adelantando desde los años 80 , lo que permitía apreciar un crecimiento económico por encima del $4 \%$ anual y un desempleo

56 LeWIN, Alfredo, "Historia de las reformas tributarias en Colombia", en autores varios Fundamentos de la Tributación, Universidad de los Andes, Editorial Temis, 2008.

57 Departamento Nacional de Planeación, Las reformas tributarias en el Siglo XX. Colombia. Giro Editores. 2002.

58 La Constitución de 1991 significó la instalación de una nueva realidad jurídica para Colombia mediante la cual se sentaron las bases del naciente sistema democrático, pluralista propio de los estados sociales de derecho. Para este fin, se incorporó en el Derecho colombiano la libertad de cultos, la acción de tutela y las acciones populares, la consolidación de la descentralización administrativa, el reconocimiento y protección de las minorías étnicas, la dignificación de los derechos fundamentales, las bases del sistema de salud a cargo del Estado, la autonomía del banco central colombiano, la defensa al medioambiente, la capacidad de censurar por parte de los órganos de representación popular los cargos de la administración y diversas entidades garantes de esta nueva realidad jurídica, tales como: la Corte Constitucional, la Fiscalía General de la Nación y la Defensoría del Pueblo, entre otros.

59 Constitución Política de 1991, artículos 330,331, y 333 -complementariamente, se puede ver el primer plan nacional de desarrollo de esta época, denominado "revolución pacífica 1990-1994", del Gobierno de César Gaviria Trujillo. 
inferior al $10 \%$. No obstante los matices económicos positivos que se podían apreciar, el comportamiento fiscal ${ }^{60}$ del sector público no financiero ${ }^{61}$ estaba encauzado en una fuerte senda de crecimiento en razón del crecimiento del Estado colombiano, que si lo analizamos en términos del producto interno bruto colombiano, el mismo paso del $21 \%$ en la década de los 90 al 39,3 \% para los primeros años de la década del 2000, situación que no se acompasó con los ingresos de este mismo sector, que solo aumentaron 16 puntos porcentuales, es decir, pasó del 20\% al 36\%, evidenciando un déficit continuado, aunado a un creciente gasto de caja del gobierno central, que aumentó respecto del producto interno bruto en 12 puntos porcentuales, pasando del 9,4\% a comienzos de la década de los 90, al 21,3\% para el inicio de la primera década del siglo XXI ${ }^{62}$.

Así las cosas, tenemos que el cierre del siglo XX y el inicio del siglo XXI en términos económicos estuvieron marcados por un desbalance fiscal continuado, lo que resultó en una serie de esfuerzos fiscales trasladados a los contribuyentes en aras de balancear nuevamente las cuentas nacionales. Bajo este entender, entre el periodo de 1990 a 2006 se realizaron 8 reformas tributarias, las cuales tuvieron la connotación necesaria de ser reformas recaudatorias a fin de corregir el desbalance fiscal expuesto.

Al efecto se analizará esta serie de reformas en el marco de la situación económica descrita:

Ley 49 de 1990 "Por la cual se reglamenta la repatriación de capitales, se estimula el mercado accionario, se expiden normas en materia tributaria, aduanera y se dictan otras disposiciones". Fue una reforma tributaria de contexto necesaria, en razón que se debía actualizar la realidad fiscal al nuevo entorno de apertura económica que se venía adelantando en la década del 80 y reforzada en el nuevo marco de realidad jurídico económica por la Constitución de 1991; aparejado a esto, como se expuso, también se hizo de relieve el esfuerzo por aumentar el recaudo, y reducir la dependencia del presupuesto público nacional al comercio exterior; al efecto se tomaron medidas de amnistía por omisiones de declaración ${ }^{63}$, el fortalecimiento del mercado de capitales ${ }^{64}$ a través de la desgravación de la venta de acciones por medio de bolsa como constitutivos de renta o de ganancia ocasional; así mismo, las capitalizaciones y los aportes a los fondos de pensiones no fueron consideradas como ingreso constitutivo de renta. En cuanto a los impuestos indirectos, se amplió la tarifa

60 El balance fiscal del Sector Público No Financiero (SPNF) corresponde al resultado obtenido, sea éste déficit o superávit, de la diferencia entre todos los ingresos que registra el SPNF, menos todos sus gastos. http://www.minhacienda.gov.co/HomeMinhacienda/politicafiscal/BalanceFiscaLSPNF/

61 Por sector público no financiero (SPNF) debemos entender a todas las entidades que conforman al gobierno nacional central, los establecimientos públicos nacionales, el sector público regional y local, así como las entidades de la seguridad social, el sector eléctrico, las empresas municipales y departamentales, entre otras entidades.

62 Junguito, Roberto; Rincón Hernán, "La Política Fiscal en el Siglo XX en Colombia", documento preparado para el seminario "Investigaciones recientes sobre historia económica colombiana", 2004. Disponible en https://core.ac.uk/download/files/153/7077619.pdf

63 Ley 49 de 1990, Artículo 1.

64 Ley 49 de 1990, Artículos 4, 5, 6, 7, 8, 9. 
del IVA del $10 \%$ al $12 \%{ }^{65}$. De otro lado, se obtuvieron facultades extraordinarias por el término de cuatro años para reducir los impuestos a las importaciones del 13\% al 8\% ${ }^{66}$.

Así las cosas, caracterizando en términos fiscales la precitada reforma además de ampliar la base y las tarifas del IVA del $10 \%$ al 12\%, es de resaltar que los ingresos del Estado se vieron fortificados junto a algunas mejoras administrativas para una recaudación más eficaz.

Ley 6 de 1992 "Por la cual se expiden normas en materia tributaria, se otorgan facultades para emitir títulos de deuda pública interna, se dispone un ajuste de pensiones del sector público nacional y se dictan otras disposiciones". Bajo la misma concepción recaudatoria de la Ley 49, el gobierno se vio en la necesidad de tramitar nuevamente otra reforma tributaria, para hacer aún más expansivos los esfuerzos de recaudo adelantados por la anterior reforma; así las cosas, esta nueva reforma básicamente se centró en el aumento del recaudo a través del aumento de la tarifa de impuestos existentes, con lo cual el IVA pasó del $12 \%$ al $14 \%{ }^{67}$; así mismo, se crearon nuevos impuestos, como las contribuciones temporales ${ }^{68}$ y especial del impuesto de renta y de la explotación de hidrocarburos dentro del territorio nacional ${ }^{69}$.

Ley 223 de 1995 "Por la cual se expiden normas sobre Racionalización Tributaria y se dictan otras disposiciones". Se formuló dentro de la dualidad del déficit vivido; si bien con las reformas de las leyes 6 y 49 se aumentó el recaudo en 2 puntos del producto interno bruto, el gasto mantuvo su senda creciente en el doble respecto del ingreso, es decir, en el $4 \%$, por lo cual fue necesario otro esfuerzo fiscal por parte de la sociedad para solventar este déficit asociado al tamaño creciente del Estado colombiano entre una de sus justificaciones al gasto creciente. Bajo este espectro, se señala que también hubo recortes de gastos y demás medidas de orden presupuestal para corregir este déficit que a su vez se apalancó con la anotada Ley 223 de 1995, estableciéndose una tarifa de retención en la fuente para rentas de capital o trabajo de un $35 \%{ }^{70}$; de igual forma, se limitó el descuento de renta sobre donaciones en un $30 \%{ }^{71}$, respecto de los impuestos indirectos se amplió la base de cobertura del IVA respecto de bienes que no causaban este impuesto y se aumentó la tarifa de este impuesto al $16 \%{ }^{72}$; se configuró el impuesto al consumo de cigarrillos y tabaco elaborado en las jurisdicciones nacionales ${ }^{73}$, y además se reformó la estructura tributaria de la tributación de los combustibles al establecer un gravamen único que sustituiría a los cuatro vigentes existentes ${ }^{74}$.

65 Ley 49 de 1990, Artículo 26.

66 Ley 49 de 1990, Artículo 79

67 Ley 6 de 1992, Artículo 19.

68 Ley 6 de 1992, Artículo 11.

69 Ley 6 de 1992, Artículo 13.

70 Ley 223 de 1995, Artículo 127.

71 Ley 223 de 1995, Artículo 87.

72 Ley 223 de 1995, Artículos 12, 13 y 14

73 Ley 223 de 1995, Artículos 207, 208, 209, 210, 211, 2012.

74 Ley 223 de 1995, Artículo 58. 
Aun cuando se realizaron diversos esfuerzos fiscales y presupuestarios, el desbalance fiscal del sector público era cada más preocupante, además de la ineficiente asignación en este periodo. La presión fiscal aumentaba constantemente, entre otros factores, por la situación de orden interno presionado por los grupos al margen de la ley suponía un incremento del gasto público en seguridad en un 1,3\% del Producto Interno Bruto, así como el aumento de las transferencias en educación y en salud aumentaron un $1 \%$, y la consolidación del creciente Estado así como su fortalecimiento ocupaba un 2,2\%, situación que alineó con un etapa de desaceleración económica ${ }^{75}$ muy fuerte: para el año 1999, sin precedente de estimación, el Producto Interno Bruto colombiano cayó un 4,5\%, lo cual terminó por profundizar la situación de déficit fiscal que para ese entonces se estimó en un $7 \%$ con una caída del $6,4 \%$ de los ingresos fiscales del gobierno ${ }^{76}$, situación que hizo necesario un nuevo paquete de reformas fiscales.

Ley 617 de 2000 "Por la cual se reforma parcialmente la Ley 136 de 1994, el Decreto Extraordinario 1222 de 1986, se adiciona la Ley Orgánica de Presupuesto, el Decreto 1421 de 1993, se dictan otras normas tendientes a fortalecer la descentralización, y se dictan normas para la racionalización del gasto público nacional". Tuvo como objeto principal buscar el saneamiento fiscal de las entidades territoriales y articular su orden presupuestal.

Ley 633 del año 2000 "Por la cual se expiden normas en materia tributaria, se dictan disposiciones sobre el tratamiento a los fondos obligatorios para la vivienda de interés social y se introducen normas para fortalecer las finanzas de la Rama Judicial". Bajo el marco económico vivido tenía una misión diáfana: más allá de los fines instrumentales fiscales como el fortalecimiento fiscal y la simplificación del sistema tributario, tenía un fin recaudatorio como herramienta principal para conjurar de forma positiva el creciente déficit del sector público. Para este efecto, se materializo el impuesto sobre el gravamen a los movimientos financieros (GMF ${ }^{77}$ establecido en el Decreto 2331 de 1998, amplió la base del IVA y su tarifa general en el $16 \%{ }^{78}$, y para efectos del impuesto sobre la renta se aumentó la renta presuntiva sobre el patrimonio líquido al $6 \%{ }^{79}$.

Las anteriores medidas junto con una fuerte política de austeridad, y una economía en proceso de reactivación reencauzaron la senda fiscal colombiana hacia la reducción del déficit consolidado del sector público que para el año de 2001 oscilaba por el 3,3\%, y se registró un crecimiento de la economía en 2,8\%; no obstante, era apremiante acompasar el crecimiento del ingreso con el del gasto para así evitar los desbalances presentados en la última década. Bajo este propósito, la administración del expresidente URIBE empezó su política fiscal con la Ley 788 de 2002 "Por la cual se expiden normas en materia tributaria preparado para el seminario "Investigaciones recientes sobre historia económica colombiana", 2004. Disponible en https://core.ac.uk/download/files/153/7077619.pdf

76 Ibíd

77 Ley 633 de 2000 Artículo 1.

78 Ley 633 de 2000 Artículos 26 y 27.

79 Ley 633 de 2000 Artículo 15. 
y penal del orden nacional y territorial $y$ se dictan otras disposiciones" con el objeto , al igual que las últimas reformas, de aumentar el recaudo con miras a reducir el imperante déficit; para este fin, nuevamente se amplió la base del IVA sobre bienes y servicios que se encontraban excluidos, se aumentaron algunas tasas diferenciales sobre algunos productos gravados con IVA ${ }^{80}$, se estableció una sobretasa al impuesto de renta del 10\% para el año 2003 y del $5 \%^{81}$ para el año 2004, se redujo la renta laboral externa del $30 \%$ al $25 \%{ }^{82}$, se limitó la deducción a los impuestos territoriales a un $80 \%$ (impuestos de industria y comercio y de predial ${ }^{83}$. De igual forma, se incrementaron las tarifas de sobretasa a la gasolina en un total del $25 \%{ }^{84}$. No obstante, la anotada reforma de estructurarse como medida de recaudo, resultó bastante contradictorio el régimen amplísimo de exenciones establecidas en la misma Ley 788, si bien se resalta el esfuerzo de impulsar la industria con estas preferencias, no deja de resultar exótica una medida fuerte de recaudo y fuerte en desgravación. Para este fin, se permitió durante 3 años descontar del impuesto sobre las ventas $100 \%$ del IVA pagado por la maquinaria adquirida ${ }^{85}$ en un periodo de tiempo. Por el lado de las exoneraciones sobre la renta, se plasmaron una serie de incentivos de inversión a cambio de la exoneración total del impuesto de renta en diversos sectores de la economía colombiana, tales como el sector eléctrico por 15 años, el sector hotelero (creación de hoteles o ampliación) por 30 años, servicios de ecoturismo por 20 años, los contratos de leasing con opción de compra para vivienda urbana, entre muchos otros.

Finalmente, se buscó desincentivar las conductas fraudulentas fiscales a través de la imposición de sanciones pecuniarias más gravosas con un tope de 200 salarios mínimos mensuales vigentes.

Posteriormente y casi de inmediato en el tiempo, la administración del gobierno del presidente URIBE, ante una imposibilidad de reducir eficazmente el déficit fiscal, recurrió nuevamente al instrumento fiscal recaudatorio, aprobado por el Congreso de la República de Colombia, se estableció una nueva reforma tributaria recaudatoria materializada por le Ley 863 de 2003 "Por la cual se establecen normas tributarias, aduaneras, fiscales y de control para estimular el crecimiento económico y el saneamiento de las finanzas públicas". Para este efecto, se aumentó la tarifa del impuesto temporal creado de gravamen a los movimientos financieros al 4 por mil ${ }^{86}$, nuevamente se reforzó la base de la tributación indirecta; para ese entonces, ya se conocían los efectos adversos e incluso regresivos que en su génesis lleva esta clase medidas, pero incluso así, se amplió la base de bienes incluidos con bajo este impuesto ${ }^{87}$, se crearon nuevas tasas para bienes exentos del IVA ${ }^{88}$; así mismo, 
para estabilizar sus efectos negativos y como una de las primeras medidas de inclusión financiera, se estableció la devolución de 2 puntos del IVA pagado por compras realizadas con tarjetas débito o crédito ${ }^{89}$.

Sobre la tributación directa, específicamente el impuesto de renta, se constituyó una sobretasa temporal del 10\%, se fortaleció el régimen para los no declarantes del impuesto de renta, en el sentido de ampliar la base de información sobre contribuyentes y obligar a declarar a más personas, se amplió la base de ingresos constitutivos de renta, se limitaron las deducciones de los impuestos de industria y comercio. De manera complementaria se estableció el impuesto al patrimonio, con un carácter temporal de 3 años, aunque ya veremos que la temporalidad pervive a nuestros días en 2016. Finalmente, se incorporaron medidas antielusión y evasión, tales como el Registro Único Tributario, sanciones a los revisores fiscales, sanción por evasión pasiva, la posibilidad de que la administración tributaria reporte ante las centrales de riesgo el no pago de impuestos.

A juicio personal, considero vital dentro del proceso de caracterización de la configuración del sistema fiscal colombiano remarcar expedición de la Ley 819 de 2003 "Por la cual se dictan normas orgánicas en materia de presupuesto, responsabilidad y transparencia fiscal y se dictan otras disposiciones", norma crucial que justificará algunas medidas de corte fiscal y que parametrizará la coyuntura económica para enfocar las herramientas fiscales y presupuestarias de Estado colombiano. A este efecto, mediante la citada Ley 819, se crearon las siguientes herramientas presupuestarias: (i) El Marco fiscal de mediano plazo ${ }^{90}{ }_{i}$ (ii) el informe de superávit primario, (iii) la obligatoriedad de que cualquier proyecto de ley, ordenanza o acuerdo que ordene gasto o que otorgue beneficios tributarios, deberá hacerse explícito y deberá ser compatible con el Marco Fiscal de Mediano Plazo, y (iv) trámite de las vigencias futuras.

Cabe agregar que la anterior medida, así como las reformas tributarias de las leyes 863 y 788, obedecen a un contexto económico determinado para ese momento. Es de señalar que el inicio del siglo arrancó con prospectivas positivas sobre la económica, en especial por la fuerte crisis económica vivida en Colombia en la década pasada, razón que justificó la medida del crecimiento de la producción en esta nueva década aumentar los ingresos y así aminorar el déficit, con la finalidad de acomodar las finanzas públicas de ese Estado colombiano crecido a gran velocidad.

Para el año 2003 la economía colombiana registró un crecimiento económico 3,74\% siendo la variación más alta desde el año 1995. Este crecimiento duplicó el de América

90 El Marco Fiscal de Mediano Plazo (MFMP) es un documento que enfatiza en los resultados y propósitos de la política fiscal. Allí se hace un recuento general de los hechos más importantes en materia de comportamiento de la actividad económica y fiscal del país en el año anterior. Presenta las estimaciones para el año que cursa y para las diez vigencias siguientes y muestra la consistencia de las cifras presupuestales con la meta de superávit primario y endeudamiento público y, en general, con las previsiones macroeconómicas. Ver más en http://www.minhacienda.gov.co/HomeMinhacienda/politicafiscal/marcofiscalmedianoplazo/ 
Latina ${ }^{91}$; este crecimiento fue creciente y sostenido para los años 2004, 2005, 2006 y 2007 oscilante entre 4 y el 7,5\% de crecimiento del PIB. Todo lo anterior ocurrió en un contexto de sano equilibrio macroeconómico, ya que el sector público redujo su déficit a 1,3\% del PIB, números que no se evidenciaban desde la década pasada.

En el sentir de este positivo escenario económico se estableció la Ley 1111 del 27 de diciembre de 2006 "Por la cual se modifica el estatuto tributario de los impuestos administrados por la Dirección de Impuestos y Aduanas Nacionales" con el fin de ajustar algunas disposiciones relativas al impuesto de renta tales como la exclusión de algunos de los sujetos pasivos de este impuesto ${ }^{92}$, así mismo se establece la renta presuntiva por la cual se presume que la renta líquida no debe ser inferior al 3\% del patrimonio líquido del contribuyente ${ }^{93}$ y se modifican la tarifas marginales de este impuesto para personas jurídicas y naturales. Por su parte se establece nuevamente una deducción del 100\% de los impuestos de industria y comercio, avisos y tableros y predial, que efectivamente se hayan pagado durante el año o período gravable siempre y cuando tengan relación de causalidad con la actividad económica del contribuyente, así mismo se establece la posibilidad de deducción sobre el gravamen a los movimientos financieros hasta un $25 \%{ }^{94}$. Se da una prórroga al impuesto al patrimonio por 4 años consecutivos adicionales, vale decir hasta el año 2010 $0^{[95]}$.

Por el lado de los impuestos indirectos, se modifica la tarifa de algunos bienes y servicios, se amplía la base de bienes y servicios gravados con IVA $^{96}$ y se establecen algunas normas procedimentales ${ }^{97}$.

91 Tabla 1. CReCimiEnTo del pib REAL En AmÉRICA LATINA

\begin{tabular}{|l|c|c|c|}
\hline \multicolumn{1}{|c|}{ Zona / País } & Promedio 1999-2001 & 2002 & 2003 \\
\hline América Latina y el Caribe & $1,6 \%$ & $-0,1 \%$ & $1,7 \%$ \\
\hline Argentina & $-2.9 \%$ & $-0,1 \%$ & $1,7 \%$ \\
\hline Brasil & $2,2 \%$ & $1,9 \%$ & $0,2 \%$ \\
\hline Chile & $2,4 \%$ & $2,2 \%$ & $3,3 \%$ \\
\hline Colombia & $0,0 \%$ & $1,8 \%$ & $3,7 \%$ \\
\hline México & $3,3 \%$ & $0.7 \%$ & $1,3 \%$ \\
\hline Perú & $1,3 \%$ & $4,9 \%$ & $4,0 \%$ \\
\hline Venezuela & $0,0 \%$ & $-8,9 \%$ & $-9,2 \%$ \\
\hline
\end{tabular}

Fuente: FMI. WEO Abril 2004.

Promedio 1999-2001

20022003

92 Ley 1111 de 2006, Artículo 1.

93 Ley 1111 de 2006, Artículos 9, 12, 13, 15.

94 Ley 1111 de 2006, Artículo 4.

95 Ley 1111 de 2006, Artículo 25.

96 Ley 1111 de 2006, Artículos 31, 32, 33 y ss.

97 Ley 1111 de 2006, Capítulo V. 
A pesar del buen momento por el que atravesaba la economía colombiana, el entorno internacional no era el más favorable y se entró en curso de una de las más grandes crisis financieras de la historia originada en el mercado inmobiliario de Estados Unidos en agosto de 2007 y que se expandió con la quiebra de un grande financiero como Lehman Brothers. Para ese entonces, se estimó que el impacto de la crisis económica en términos de pérdida de riqueza podría equivaler al PIB mundial en un año, producto del choque económico generado por el descalabro financiero profundizado por la pérdida de la confianza y del incremento de la aversión al riesgo de los agentes. Estos efectos generaron un decaimiento de las economías más desarrolladas y, en consecuencia, el decaimiento en la demanda externa, lo que afectó los términos de intercambio con economías emergentes como la colombiana, que tuvo por efecto inmediato una reducción importante en las exportaciones de Colombia para esos países. Además se debe tener en cuenta que esta crisis no solo afectó en términos de intercambio y de inversión extranjera en el territorio colombiano, también significó una menor disponibilidad del crédito externo y un encarecimiento del mismo.

Bajo este contexto de crisis económica mundial y de gran incertidumbre sobre su proceso de recuperación, y previendo un decaimiento de los ingresos por parte del sector real, el gobierno colombiano efectuó política contracícilica que tuvo "como objetivo primordial la minimización de sus efectos sobre el crecimiento y el empleo. Esta estrategia se fundamenta en i) La adopción de una postura fiscal razonablemente anticíclica, la cual permite que la caída en los ingresos fiscales como resultado de la desaceleración económica se transfiera al déficit, manteniendo la deuda en una senda sostenible. Esto se acompaña con una priorización del gasto público enfocada en gastos en infraestructura y de dinamización de la actividad productiva privada, ii) Garantizar la financiación interna y externa de la Nación, iii) Garantizar el financiamiento interno de la actividad productiva, y iv) Proteger el empleo"

En este sentido, resulto imperativo modificar el régimen tributario a fin de garantizar el nivel de ingresos que permitiría en el mediano plazo mantener controlado el déficit presupuestario del sector público. Con este objetivo, se aprobó por el Congreso de la República de Colombia la Ley 1370 de 2009 "Por la cual se adiciona parcialmente el estatuto tributario" en el sentido de crear el impuesto al patrimonio a cargo de las personas jurídicas, naturales y sociedades de hecho, contribuyentes declarantes del impuesto sobre la renta por el año 2011.

La anterior coyuntura, como se esperaba, afectó la economía colombiana que para el año 2009 arrojó un crecimiento del $0,4 \%$ en su $\mathrm{PIB}^{99}$; no obstante, el resultado de decrecimiento comparado con otras naciones resultó favorable: así, para el año 2010, las economías mundiales comenzaron un proceso asimétrico de recuperación que se representó en un crecimiento ponderado del 3\% para economías desarrolladas y de $7,5 \%$ para economías emergentes, como la colombiana ${ }^{100}$. A pesar de este incipiente 
crecimiento, la recuperación de las primeras economías del mundo trajo consigo presiones inflacionarias sobre las economías emergentes, vía aumento del precio de consumo en estas economías dependientes, el mejor ejemplo para ilustrar este fenómeno fue la carrera en el ascenso del precio del petróleo, para ese momento específico el barril de petróleo mostraba un aumento de 40 dólares en su precio, claro está que sobre este bien en particular influyeron factores exógenos a los enunciados, como las situaciones bélicas de los mayores productores de ese momento, así como la incertidumbre del mercado sobre la provisión del bien ${ }^{101}$.

Así las cosas, se detectó nuevamente la necesidad de adaptar la política fiscal acorde con esta realidad de reactivación económica, presiones inflacionarias e intención de captar más ingresos provenientes de las rentas de la explotación de petróleo nacional. Así se estableció una vez aprobada por el Congreso de la República de Colombia La ley 1430 del 29 diciembre de 2010 "Por medio de la cual se dictan normas tributarias de control y para la competitividad", cuyo objetivo principal fue generar nuevas condiciones impositivas en pro del desarrollo del sector industrial colombiano, en condiciones similares a los demás países de la región, debido a que se detectó una desventaja comparativa del sector industrial colombiano consistente en el mayor costo de producción asociado a las sobretasas; así las cosas, el gobierno colombiano consideró que el retiro de sobretasas a la industria podría incentivar la creación de industrias, así como una mayor competitividad, lo cual se debía traducir en un esfuerzo fiscal para cubrir el déficit creado al retirar las anotadas sobretasas.

Por el lado de la tributación directa se eliminó la deducción especial en el impuesto de renta por inversión en activos fijos reales productivos ${ }^{102}$, se declararon exentos de este impuesto sujetos de carácter social como los hogares comunitarios ${ }^{103}$ y se modificó el régimen de ingresos de fuente nacional constitutivos de renta ${ }^{104}$. Se eliminó la sobretasa del sector eléctrico para industriales a partir del año 2012 ${ }^{[105]}$. Además se aumentó el porcentaje deducible del $25 \%$ al $50 \%$ de gravamen de movimientos financieros ${ }^{106}$.

De manera complementaria, se modificó la operatividad del tax credit o crédito de impuesto sobre los impuestos pagados en el exterior, retirando la limitación a que el crédito de impuesto no se limite a impuestos pagados en el exterior por sociedades en las cuales se tiene inversión directa, sino también admitir el descuento por los impuestos pagados por sociedades de participación indirecta a través de sociedades filiales y subsidiarias, denominado crédito fiscal indirecto ${ }^{107}$. Finalmente, se aceptó como concepto

101 Ministerio de Hacienda y Crédito Público. Marco Fiscal de Mediano Plazo del año 2011.

102 Ley 1430 de 2010, Artículo 1.

103 Ley 1430 de 2010, Artículos 23 y 24.

104 Ley 1430 de 2010, Artículo 65.

105 Ley 1430 de 2010, Artículo 2.

106 Ley 1430 de 2010, Artículo 45.

107 Ley 1430 de 2010, Artículo 46. 
de deducibilidad del impuesto de renta el pago a agremiaciones ${ }^{108}$, entre otras normas relativas al impulso industrial en Colombia en torno a la coyuntura mundial.

Como nota al margen, pero por ser esencial dentro de la comprensión del sistema fiscal colombiano, es preciso hacer hincapié en los años 2011 y 2012, cuando se crearon diversas figuras de orden fiscal y presupuestario a fin de evitar ciclos deficitarios como los vividos en la década del noventa y por los cuales se vivió una de las más grandes depresiones de la economía colombiana. Bajo esta lógica se creó la regla fiscal en la Ley 1473 de 2011 y el Acto Legislativo de Sostenibilidad Fiscal materializado (Acto Legislativo 3 de 2011) y el Fondo de Ahorro y Estabilización Fiscal y Macroeconómica, normas encaminadas a mantener la disciplina fiscal de las finanzas del sector público central colombiano y capitalizar la perspectiva de mayores ingresos generados por la mayor producción del sector minero energético colombiano y sus crecientes precios internacionales.

El escenario para este momento era favorable: las buenas condiciones económicas locales, aunadas al crecimiento del gasto relativo al PIB en un 5\%, marcaban un derrotero estable y de crecimiento económico para Colombia; por esta razón, se pensó, contrario de la lógica fiscalista colombiana de los últimos 100 años, en idear una reforma estructural y no relativa a solventar alguna coyuntura económica y presupuestal. Bajo estos presupuestos se pensó nuevamente en modificar el sistema tributario colombiano con el objetivo de abaratar los costos laborales, aumentar la rentabilidad del aparato productivo, lo que habría de traducirse, en teoría, en una mayor tasa de crecimiento, particularmente en los sectores intensivos en mano de obra ${ }^{109}$ y de fines redistributivos, con lo cual se buscó corregir inequidades en la estructura tributaria a fin de reducir la desigualdad característica de las economías emergentes de la zona.

Para el año 2012, y con el propósito de materializar los objetivos descritos, una vez aprobada por el Congreso, se modificó nuevamente el sistema tributario colombiano mediante la Ley 1607 de 2012 "Por la cual se expiden normas en materia tributaria y se dictan otras disposiciones", reforma que modificó ampliamente el régimen del impuesto renta y de retención en la fuente para personas naturales y jurídicas. Dentro de las modificaciones más importantes se denota: una reducción de la tarifa del impuesto de renta del 33\% al $25 \%{ }^{110}$ y se creó un nuevo impuesto denominado el impuesto para la equidad conocido por las siglas $\mathrm{CREE}^{111}$, sobre el cual es pertinente decir que tiene matices similares en cuanto a la base gravable con el impuesto de la renta, diferenciándose que es exclusivo para personas jurídicas.

Por su parte, se modificaron los criterios de residencia fiscal ${ }^{112}$ y se incorporaron dentro de la legislación nacional conceptos como: sede efectiva de administración y de establecimiento permanente para las sociedades comerciales. Se cambiaron las reglas 
de tributación sobre distribución de dividendos ${ }^{113}$ y de utilidades, así como de prima ${ }^{114}$ y capitalización de acciones ${ }^{115}$ en las sociedades comerciales, y se modificó la tarifa del impuesto de ganancias ocasionales del 33\% al 10\% ${ }^{116}$.

Respecto de la tributación indirecta, se realizaron bastantes modificaciones sobre la base gravable y las tarifas de este impuestos, que al efecto se resumen así: (i) se simplificaron las tarifas del IVA quedando solo tres segmentos del 0\%, 5\% y del 16\%; (ii) se modificó la base a través de inclusiones o exclusiones de bienes y servicios gravados con este impuesto ${ }_{i}$ (iii) se disminuyó la tarifa de retención en la fuente en materia de IVA; (iii) se modificaron los plazos de declaración del IVA a 12 meses, 4 meses y 2 meses según su nivel de ingresos o calidad de contribuyente, (iv) se creó el impuesto al consumo ${ }^{117}$, y (v) se sustituyó el impuesto global a la gasolina y al ACPM consagrado en los artículos 58 y 59 de la Ley 223 de 1995, y el IVA a los combustibles consagrado en el Título IV del Libro III del Estatuto Tributario y demás normas pertinentes, por el Impuesto Nacional a la Gasolina y al ACPM ${ }^{118}$.

Finalmente, se reforzaron las normas antielusión y antievasión a través de la figura de abuso en materia tributaria ${ }^{119}$ y derogatoria de la Ley 963 de 2005, mediante la cual se regulaban los contratos de estabilidad jurídica ${ }^{120}$, así como un régimen transitorio de amnistías parciales para morosos de tributos y facultades de conciliación y/o terminación de procesos contenciosos tributarios ${ }^{121}$.

Para el año 2013 y con la pre-expuesta reforma 1607, las perspectivas económicas de Colombia eran favorables: la evidente recuperación del Producto Interno Bruto colombiano arrojando un crecimiento del 4,3\% con la inflación más baja de los últimos 58 años y la menor en la región ubicándose en 1,94\% aunado a una tasa de desempleo rondando el 9,6\%. En el contexto internacional, la situación mostraba también indicios de recuperación al mostrar un crecimiento anual del 3\%, principalmente apalancado por Estados Unidos ${ }^{122}$.

Pero si bien las perspectivas colombianas resultaban racionalmente optimistas sobre la senda económica creciente observada, hubo varios factores que confluyeron para mermar el ritmo de expansión de la economía colombiana, que a finales de 2014 registró una tasa de crecimiento del 4,6\%. Por una parte, el crecimiento de la economía mundial estuvo por debajo de lo presupuestado, situación que repercutió directamente en la disminución de la demanda de bienes en general, en especial, en los bienes energéticos en los cuales

113 Ley 1607 de 2012, Artículos 89, 90, 92, 95 y 96.

114 Ley 1607 de 2012, Artículo 187, 188.

115 Ley 1607 de 2012, Artículo 91.

116 Ley 1607 de 2012, Artículos 106 y 107.

117 Ley 1607 de 2012, Capítulo III.

118 Ley 1607 de 2012, Artículos 167, 168, 169, 170 y 171.

119 Ley 1607 de 2012, Artículos 122, 123, 124.

120 Ley 1607 de 2012, Artículo 166.

121 Ley 1607 de 2012, Artículos 147, 148, 150.

122 Ministerio de Hacienda y Crédito Público, Marco Fiscal de Mediano Plazo del año 2014. 
Colombia tenía una relativa dependencia. Junto al decaimiento de la demanda, se sumó el desplome de los precios del petróleo, principalmente por el explosivo aumento de la producción petrolera de Estados Unidos que para ese año abarcó el 15\% de la producción mundial, con lo cual la referencia de los precios del petróleo se disminuyó en un $40 \%{ }^{123}$.

En el entorno nacional, se registró una ligera desaceleración del crecimiento de la construcción, por el decaimiento de la construcción de edificaciones; por otra parte, el sector agropecuario no conservó el dinamismo excepcional de 2013 y ante los factores de producción nacional, la caída de los ingresos energéticos, el desbalance fiscal se empezó a acentuar vía disminución de los ingresos ordinarios del gobierno central colombiano.

En el ámbito fiscal, los balances del sector público no financiero y del gobierno central fueron deficitarios en 2014 y equivalentes al -1,8\% del PIB y el -2,4\% del PIB, respectivamente ${ }^{124}$.

Conforme la nueva realidad económica y unas perspectivas no favorables económicas internas producidas por la disminución de la producción nacional y de la ralentización de la recuperación económica mundial, junto al desplome de los ingresos energéticos y de una desfinanciación eventual del presupuesto público por la pérdida de vigencia de 2 importantes impuestos, como el gravamen a los movimientos financieros y el impuestos al patrimonio, se justificó la necesidad de modificar nuevamente el sistema tributario para hacer frente a estas coyunturas económicas y fiscales, vía aumento de la imposición. Siendo esto así, se aprobó por parte del Congreso de la República de Colombia la Ley 1739 de 2014 "Por medio de la cual se modifica el Estatuto Tributario, la Ley 1607 de 2012, se crean mecanismos de lucba contra la evasión y se dictan otras disposiciones".

La anotada reforma la podríamos identificar como una reforma neta de recaudo, es decir, su finalidad se circunscribió a aumentar los ingresos del sector público. Bajo este paradigma, se incorporaron en el sistema legal colombiano las siguientes medidas.

En lo relativo al régimen de renta, se realizaron algunos ajustes al régimen de residencia fiscal de las personas naturales ${ }^{125}$, sobre el régimen de exenciones para operaciones de crédito público y la modificación de tarifa para ingresos de fuente nacional de sociedades comerciales no residentes en Colombia ${ }^{126}$.

Se creó el impuesto extraordinario a la riqueza, que no es más que la extensión del ya conocido impuesto al patrimonio con el fin de mantener este recaudo en el tiempo ${ }^{127}$; resultó novedosa la ampliación de este impuesto a: (i) personas naturales no residentes; (ii) sociedades y entidades extranjeras, respecto de la riqueza poseída de forma directa o indirecta en el país y se incluye a (iii) las sucesiones ilíquidas y sociedades de hecho.

123 Ministerio de Hacienda y Crédito Público, Marco Fiscal de Mediano Plazo del año 2015.

124 Ibíd.

125 Ley 1739 de 2014, Capítulo IV.

126 Ley 1739 de 2014, Artículo 28.

127 Ley 1739 de 2014, Capítulo I. 
Se creó la sobretasa al CREE para el periodo de 2015 a $2018^{[128]}$. Así mismo, se extendió la vigencia del gravamen a los movimientos financieros hasta el año 2021, con una tarifa decreciente en los años sucesivos ${ }^{129}$.

Ahora bien, respecto de normas para la lucha contra la evasión, se previeron medidas de normalización tributaria ${ }^{130}$ con el fin crear incentivos de acción voluntaria para declarar los activos omitidos por parte de los contribuyentes, bajo unas condiciones especiales, y se determinaron algunas reglas para la declaración de activos en el exterior por parte de los residentes fiscales en Colombia ${ }^{131}$.

Como innovación, se dio la creación legal de la Comisión de Expertos en asuntos tributarios, cuyo objeto es estudiar el sistema tributario y proponer reformas para hacerlo más equitativo y eficiente, con lo cual se busca una racionalización de la estructura tributaria y evitar las distorsiones excesivas de este sistema en los mercados debido a una carga excesiva, que terminaría por restarles eficiencia asignativa a los mercados colombia$\operatorname{nos}^{132}$. Posterior a la reforma tributaria de 2014, para los años 2015 y 2016 la situación macroeconómica no tenía el dinamismo esperado: Estados Unidos crecía por debajo de lo esperado, Europa y Japón enfrentaban serios retos en materia de crecimiento, y China se enfocó más en el consumo que en la inversión, lo cual tuvo un afección directa sobre los macroindicadores colombianos, sumado a una inestabilidad generada por la caída de los precios del petróleo ${ }^{133}$, una inflación al alza y una tendencia creciente del gasto público enmarcada principalmente con estrategias asociadas a la reducción de la pobreza y del proceso de paz y reincorporación con los grupos armados al margen de la ley.

En el marco de lo descrito, es preciso hacer hincapié en la reducción de las rentas petroleras (impuestos pagados por empresas del sector petrolero y dividendos de Ecopetrol) que pasaron del 3,3\% en el año 2013 del PIB al -0,1\% del PIB al año 2016, lo que permite evidenciar un contracción del PIB en 3,4\%. Sumado a esto, la devaluación del peso colombiano ha encarecido el endeudamiento externo. Como consecuencia de estas medidas, el gobierno colombiano empleó una serie de medidas de austeridad reduciendo el gasto en 1,2\% del PIB y elevó el recaudo en 1,5\% con la citada reforma de $2014^{[134]}$.

Lo anterior sobre la base jurídica de dar estricto cumplimiento a los criterios de sostenibilidad y regla fiscal, justificó teóricamente, desde lo presupuestal y económico, la necesidad de una nueva reforma tributaria.

Si bien esta nueva reforma obedece a la continua y perpetuada práctica colombiana de tomar decisiones al margen (incrementalismo) y no como un proceso articulado de política pública, esta última reforma tributaria contó con muchos observadores técnicos en su estructuración, lo cual no es un indicador de garantía, pero sí de tecnicismo formal en 
la formulación de política fiscal. Siendo esto así y previo a la radicación de la Ley 1819 de 2016 "Por medio de la cual se adopta una reforma tributaria estructural, se fortalecen los mecanismos para la lucba contra la evasión y la elusión fiscal, y se dictan otras disposiciones", la Organización para la Cooperación y el Desarrollo Económico (OCDE), la Comisión de Expertos y el Banco Interamericano de Desarrollo formularon propuestas para esa necesaria reforma estructural ${ }^{135}$.

Dentro de las principales modificaciones de esta reforma de carácter estructural se resaltan las siguientes: (i) modificación de la estructura de cálculo del impuesto de renta y eliminación del CREE para personas jurídicas y naturales, (ii) se implementaron mecanismos para disminuir la evasión fiscal, (iii) se modificó el régimen tributario de las entidades sin ánimo de lucro, (iv) se crearon mecanismos para promover la formalización, (v) se modificó el régimen del IVA y establecieron unos puntos específicos del recaudo para la educación y la salud, (vi) se amplió la base gravable del impuesto al consumo, (vii) se crearon los impuestos verdes, (viii) se creó la contribución nacional de valorización y (ix) se establecieron beneficios tributarios para el posconflicto.

En cuanto al impuesto de renta, se resalta la implementación de un sistema de tipo cedular para calcular el impuesto de renta y complementarios, es decir, se introdujo una nueva metodología de cálculo en la que se clasifican las rentas según la fuente de obtención, con el fin de realizar depuraciones individualizadas que permitan configurar una base gravable pormenorizada. Con esta nueva forma de determinación quedó eliminado el sistema de liquidación de impuesto de renta basado en una clasificación de personas (empleado, trabajador por cuenta propia y otros), migrando a un sistema que toma como referencia la clasificación de rentas según su origen. Así pues, una persona natural que obtenga rentas de diferentes tipos de fuentes podrá aplicar el régimen correspondiente a cada una de ellas.

De conformidad con lo anterior, la reforma tributaria del año 2016 estipula la separación de rentas de los contribuyentes en 5 cédulas $^{136}$, a saber: (i) rentas de trabajo, (ii) rentas de pensiones, (iii) rentas de capital y (v) dividendos y participaciones. En consecuencia, el contribuyente deberá agrupar sus ingresos del año según las cinco fuentes señaladas y depurar cada tipo de forma independiente ${ }^{137}$.

135 Comisión de Expertos para la Equidad y La Competitividad Tributaria. Informe Final Presentado al Ministro de Hacienda y Crédito Público. Bogotá, 2015. "La Comisión encontró que el régimen tributario colombiano presenta limitaciones importantes : i) el bajo nivel de recaudo frente al potencial; ii) una limitada contribución a mejorar la distribución del ingreso; iii) poca equidad horizontal pues aplica un tratamiento diferente a personas y empresas similares; iv) es difícil de administrar; v) no contribuye suficientemente a la inversión, el empleo, el crecimiento y la competitividad; y, vi) cuenta con altos niveles de evasión, elusión y contrabando, que generan inequidad tributaria y desconfianza en la administración".

136 Ley 1819 de 2016, Artículo 1.

137 Una vez realizado dicho procedimiento, habrá que detraer los ingresos no constitutivos de renta, costos, gastos, deducciones, rentas exentas, beneficios tributarios y demás conceptos pertinentes, para vincular cada uno de estos conceptos a una unidad generadora de ingresos. Así mismo, el contribuyente debe garantizar que no asignó un mismo beneficio de descuento en varias cédulas. 
En concordancia con lo anterior, la reforma derogó el Impuesto Mínimo Alternativo Nacional -IMAN-y el Impuesto Mínimo Alternativo Simple -IMAS-, quedando solamente el sistema cedular como única forma de calcularlo el impuesto de renta y complementarios.

Por otra parte, la reforma tributaria trajo consigo un impacto inmediato en lo que respecta a la retención en la fuente en dos aspectos fundamentales: uno, en la derogatoria de la retención mínima, y dos, en el procedimiento de depuración.

En cuanto al objetivo de progresividad, la reforma creó un gravamen a los dividendos con tarifas del 5\% para quienes reciban más de \$18 millones y del 10\% para quienes reciban más de $\$ 30$ millones $^{138}$. En igual sentido, se redujeron los beneficios tributarios, limitando las exenciones y las deducciones al $40 \%$ del ingreso total, que en todo caso no puede exceder de $\$ 160$ millones. Esta limitación no afecta los aportes obligatorios a salud y pensión de las personas naturales.

Se eliminaron los controversiales sistemas de determinación del impuesto de renta IMAN y el IMAS, por resultar poco eficientes de administrar tanto para contribuyentes como para la administración pública.

En cuanto al impuesto de renta para sociedades ${ }^{139}$, y en aras de la deseada simplicidad fiscal, se unificaron todos los impuestos atados a la renta, de tal suerte que, a partir del año 2019, solo existirá el impuesto de renta, con lo cual se eliminó el CREE, su sobretasa y el impuesto a la riqueza; en consecuencia, a partir de 2019 el impuesto para personas jurídicas quedará establecido en tarifa única del $33 \%{ }^{140}$.

En atención a diversas recomendaciones sobre competitividad, acertadamente en esta reforma se estableció la posibilidad, para las sociedades, de deducir del impuesto sobre la renta el IVA sobre los bienes de capital utilizados en procesos productivos; es decir, lo que compren para expandirse, mejorar los negocios e invertir (maquinarias, fábricas, nuevas tecnologías, entre otras) ${ }^{141}$.

Se actualizó el lenguaje tributario con las nuevas Normas Internacionales de Información Financiera - NIIF; de tal armonización Colombia pasará de 4 sistemas contables (Decreto 2649 de 1993, NIIF, Conciliación Fiscal y Libro tributario) a un único sistema que realiza la conciliación fiscal directamente a partir de la contabilidad NIIF ${ }^{142}$.

Frente a la necesidad de controlar la evasión, la reforma presentada y aprobada por el Congreso de la República de Colombia se centró en 3 aspectos fundamentales y en concordancia con lo recomendado por los organismos internacionales y la Comisión de Expertos: (i) fortalecer el ente fiscalizador (DIAN), para lo cual se incluyeron normas

No debe olvidarse que las pérdidas de una cédula solo pueden ser compensadas dentro de la misma cédula y, una vez agotado el procedimiento, se tendrá la renta líquida cedular por cada una de las fuentes de ingresos.

138 Ley 1819 de 2016, Artículo 6.

139 Ley 1819 de 2016, Artículo 100.

140 Durante el 2017 la tarifa será del 34\% más 6\% de sobretasa, y para el 2018 del 33\% más 4\% de sobretasa. La sobretasa solo aplica a las empresas que tengan utilidades mayores a $\$ 800$ millones.

141 Ley 1819 de 2016, Artículo 67.

142 Ley 1819 de 2016, Artículos 113 y ss. 
que aseguran una modernización tecnológica de la administración de impuestos, la carrera administrativa y fortalecimiento de los mecanismos de provisión de empleo; (ii) mecanismos de lucha contra la evasión: lo cual se penalizó a la evasión de impuestos: Colombia era uno de los pocos países del mundo que no tenía un delito específico para quienes evadan impuestos, la reforma creó un tipo penal para la evasión del IVA y para el impuesto de renta, tipificación que en la realidad puede significar hasta 9 años de cárcel $^{143}$; así mismo, (iii) incluyeron normas para evitar el abuso del derecho ${ }^{144}$, el desvío de utilidades hacia jurisdicciones de baja tributación ${ }^{145}$.

En cuanto a las entidades sin ánimo de lucro, se implementan una serie de controles que aseguran que no sea un canal de evasión de impuestos ${ }^{146}$. Así, conservarán los beneficios tributarios las entidades que ejerzan una de las 13 actividades meritorias (salud, educación, cultura, deporte, etc. $)^{147}$, que permitan el acceso de la comunidad y que demuestren que reinvierten todos sus excedentes en el desarrollo del objeto social. Para este propósito, solo serán admitidas en este régimen las entidades que aprueben el proceso de calificación que realizará la DIAN ${ }^{148}$; por consiguiente, todas aquellas entidades que no superen este filtro deberán pagar los impuestos aplicables a las sociedades comerciales ${ }^{149}$. De forma complementaria, se obliga a estas entidades a hacer pública la información sobre su actividad, relativa al patrimonio, composición de los órganos directivos, pagos y fuentes de financiamiento, entre otros.

Ahora bien, en cuanto a las medidas de formalización, la precitada reforma del año 2016 creó el monotributo, un impuesto opcional y alternativo para pequeños comerciantes que en su momento eran sujetos de declarar renta pero que no estaban en la obligación de facturar IVA ${ }^{150}$.

Una de las medidas más controversiales de esta reforma fue el aumento de la tarifa del IVA del $16 \%$ al 19\%. Este aumento se destinó específicamente, así: 0,5 puntos del IVA, equivalentes a $\$ 1,3$ billones de pesos, se destinarán anualmente al aseguramiento y calidad del sector salud de los colombianos; 0,5 puntos del IVA, equivalentes a $\$ 1,3$ billones de pesos, se destinarán anualmente a la financiación de la educación, el $40 \%$ de este recaudo se destinará a la financiación de la Educación Superior Pública y a programas de becas y créditos educativos a través del Icetex ${ }^{151}$.

Como medida de vanguardia, esta reforma incursionó en la tendencia internacional de los impuestos verdes; para este objetivo, la reforma creó un impuesto sobre las emi- 
siones de carbono de todos los combustibles fósiles ${ }^{152}$. Por otro lado, la reforma creó un impuesto al consumo de bolsas plásticas para estimular el uso de bolsas reutilizables y biodegradables. El impuesto aumentará su tarifa progresivamente: \$20 en 2017, \$30 en 2018 , $\$ 40$ en 2019 y $\$ 50$ a partir de $2020^{[153]}$.

Corolario de la reforma, y como medida apalancadora del posconflicto, se crearon las Zonas más Afectadas por el Conflicto - ZOMAC ${ }^{154}$ : las micro y pequeñas empresas que se establezcan en estas zonas, tendrán una tarifa de impuesto de renta del $0 \%$ por los años 2017 a 2021 ; del 8,25\% por los años 2022 a 2024 y del 16,5\% para los años 2025 a 2027. Para las medianas y grandes empresas, la tarifa será del 17\% para el año 2017, del 16,50\% por los años 2018 a 2021, y del 24,75\% por los años 2022 a $2027^{[155]}$.

Finalmente, será necesario esperar las reglamentaciones y los conceptos de la administración tributaria para tener certeza de la interpretación que deberá darse a estos temas, así como a los demás aspectos de esta reforma tributaria con miras a poder medir sus efectos e impactos en la realidad.

\section{c. Delimitación de la competitividad a efectos de este estudio}

Bajo una de las múltiples perspectivas que nos puede brindar el Análisis Económico del Derecho, la realidad fiscal puede matizarse bajo la lógica de la competitividad a fin de obtener o de medir qué tan óptimo es el sistema tributario para el sector público y privado, el cual debe generar un nivel de distorsión mínimo en los mercados; todo esto, sobre la base de que en la actualidad las personas, (jurídicas y naturales) así como los capitales, se mueven con bastante facilidad. Siendo esto así, abordar el término de competitividad en el ámbito fiscal resulta ser indispensable para la consecución de una economía exitosa y un país más competitivo. En virtud de lo anterior, se resaltan las condiciones ideales, ampliamente estudiadas por la economía, que debe ostentar cualquier sistema tributario, así:

- Eficiencia: este principio rector hace referencia a que la estructura tributaria de cualquier país debe evitar ser una distorsionadora de la economía y propender por la eficiencia de los mercados.

- Sencillez administrativa: tiene un enfoque dual: por un lado, los sistemas tributarios deben ser fáciles de administrar por parte del sector público, y fácil de cumplir por parte de los administrados

- Flexibilidad: es la capacidad positiva de adaptación de los sistemas tributarios a las coyunturas.

- Transparencia: es la condición de un sistema tributario en la cual está claro quién paga un impuesto y quién se beneficia. 
- Equitativo: el sistema tributario debe perseguir los conceptos normativos de la equidad horizontal y vertical ${ }^{156}$.

Conforme lo anterior, como primer apuntalamiento para acotar el término competitividad fiscal, se hace referencia debida al óptimo, en cuanto su estructura y funcionamiento, en la medida que no sustraiga los beneficios propios del libre mercado a través de la conocida neutralidad fiscal (un impuesto que no distorsione la elección de los proyectos de inversión) ${ }^{157}$; no obstante, los sistemas tributarios no se estructuran con base en la neutralidad fiscal, la realidad tributaria resulta ser compleja al estar en choque constante la eficiencia, la equidad y el tiempo: uno como determinante del deber ser del sistema, otro como finalidad social del mismo y, por último, el tiempo que, siendo el elemento accidental, termina por ser el más determinante dentro de la estructura tributaria, porque, se quiera o no reconocer, la finalidad principal del sistema tributario no es corregir eventualidades de los mercados ni de la realidad social sino generar el recaudo público. Así las cosas, es común encontrar en la realidad de los sistemas tributarios el choque constante entre los anotados objetivos y coyunturas temporales; por ejemplo, la equidad dictaría preferencia hacia un sistema de tributación directa con tasas marginales diferenciales entre los sujetos, mientras que la eficiencia se podría inclinar por tributación indirecta con tasa única, y escogencia de una opción u otra dependerá de la ideología de los gobiernos de turno, del nivel de déficit fiscal, del grado de desarrollo económico del país y de su capacidad administrativa, de la estructura económica y de los grupos de interés entre otros elementos. En consecuencia, todos estos factores moldean en la práctica el sistema tributario de un país y limitan su dinamismo y, por qué no, su capacidad de incrementar su competitividad.

Por otro lado, aludir a la competitividad fiscal también debe corresponderse a ser una herramienta optima fiscal, mediante la cual los Estados puedan conseguir los recursos de una forma eficiente (donde el recaudo tenga un coste menor que el valor recaudado) y donde la acción recaudatoria también sea eficaz en su finalidad. Por parte de los administrados, la competitividad fiscal también debe referirse a un régimen impositivo simple y transparente, en el que cumplir con las obligaciones fiscales no les represente un coste adicional al propio del gravamen del impuesto.

Así las cosas, el término de competitividad fiscal se puede predicar de un sistema tributario que: (i) evite distorsionar los mercados ${ }^{158}$, para lo cual mantendrá una pre-

156 Stiglitz, Joseph, La Economía del Sector Público, Antoni Bosch, tercera edición, 2003.

157 StigliTZ, JosePh, La Economía del Sector Público, Antoni Bosch, tercera edición, 2003.

158 PeRRY, GUILLERMO, "Impuestos Nacionales y Locales, Hacia una reforma tributaria estructural" "al pagar impuestos, los hogares y las empresas quedan con menos recursos para consumir, ahorrar e invertir. En adición, los tributos pueden distorsionar la asignación de recursos en la economía, imponiendo costos adicionales sobre el crecimiento económico. Un buen sistema tributario debe evitar gravar en exceso la inversión y el ahorro y distorsionar en forma inconveniente la asignación de los factores de producción. Así, desde el punto de vista de la eficiencia económica, el sistema tributario óptimo sería uno que solamente grava el consumo, que tuviese tasas bajas y que fuera "neutro" entre actividades (con excepción 
sión fiscal competitiva ${ }^{159}$ (es un criterio que se debe analizar en conjunto de referencia frente a otros sistemas tributarios), y (ii) tenga un sistema de administración tributario eficiente ${ }^{160}$, en cuanto a sus costes de administración y recaudación, así como de manejo simple por parte de los contribuyentes.

Colofón de esta sección del presente estudio, resulta en afirmar que la competitividad en general, si bien es un concepto que puede dar lugar a debate académico, su desarrollo como objetivo medible y contrastable permite obtener datos entre el desempeño de diferentes dimensiones entre las naciones, por ejemplo la tributaria, dimensión en donde la mayoría está de acuerdo en que es una variable necesaria para el desarrollo económico sostenible de una Nación. Si bien existen diversas organizaciones que miden la competitividad a través de índices anuales con métodos diferentes, para la presente investigación se tomó el Informe Nacional de Competitividad y el informe realizado por el Banco Mundial, denominado Paying Taxes; de tal designio resulta cuestionable que Colombia se haya mantenido en el mismo nivel de competitividad en los últimos 5 años $^{161}$, aun cuando sus gastos han aumentado de media en un 10,29\% en los últimos

de unas pocas que poseen externalidades positivas indiscutibles -por ejemplo, investigación y desarrollo, servicios de educación y salud, reforestación-). En adición, debería evitar la doble tributación internacional o nacional y los impuestos indirectos deberían gravar los bienes y servicios importados en forma idéntica a los domésticos (excepto por un arancel, ojalá bajo y uniforme) y exceptuar las exportaciones, ya que éstas serán gravadas en el país de destino" Colombia 2010-2014: propuestas de política pública, Corporación Andina de Fomento - Fedesarrollo, 2010.

159 Pormelau, Kyle; COlE, Alan, "International Tax Competitiveness Index" "While the corporate income tax rate is a very important determinant of economic growth and competitiveness, it is not the only thing that matters. Several factors determine the competitiveness of a tax code; the structure and rate of corporate taxes, cost recovery of business investment, property taxes, income taxes, and tax rules for foreign earnings are some of the factors that determine whether a country's tax code is competitive.

Many countries have been working hard to improve their tax codes. New Zealand is a good example of one of those countries. In a 2010 presentation, the chief economist of the New Zealand Treasury stated, "Global trends in corporate and personal taxes are making New Zealand's system less internationally competitive." In response to these global trends, New Zealand cut its top marginal individual income tax rate from 38 percent to 33 percent, shifted to a greater reliance on the goods and services tax, and cut its corporate tax rate to 28 percent from 30 percent. This followed a shift to a territorial tax system in 2009. New Zealand added these changes to a tax system that already bad multiple competitive features, including no inheritance tax, no general capital gains tax, and no payroll taxes." Tax Foundation, 2015, disponible en: http://taxfoundation. org/sites/default/files/docs/TF_ITCI_2015.pdf

160 Analizar desde la eficiencia y la competitividad a la administración tributaria es entender que la operatividad pública del sistema tributario tiene costes fijos de administración y costes variables, así como costes para los administrados adicionales al cumplimiento del tributo; de esta forma, el sistema tributario más eficiente y competitivo será aquel que minimice los costes por peso recaudado, con lo cual se tendría un sistema tributario simple (de pocos tributos) regímenes y tarifas únicas, muy pocas exenciones y burocracia reducida.

161 Consejo Privado de Competitividad. Índice Nacional de Competitividad 2016-2017. Este informe recoge el balance de la competitividad fiscal colombiana en los últimos 10 años, analizando los principales impuestos en Colombia (Renta, IVA, GMF, riqueza y recaudo), donde se resalta la estática capacidad de movilidad y mejora del sistema, apreciándose de media una constante de ausencia de competitividad. 
10 años ${ }^{162}$, lo cual nos permite afirmar, obviando otros efectos de causalidad, que un aumento del gasto no representa per se un aumento de la competitividad fiscal sino que, de hecho, puede concluirse de manera rápida y por una simple deducción cuantitativa que la presión derivada de un mayor gasto es una causa que afecta la competitividad del sistema tributario.

En suma de lo anterior, y como se puede seguir de la línea argumentativa de la competitividad, esta reviste diversos áreas de medición y análisis; a efectos de esta investigación, solo se tomará como referente de análisis y medición el incrementalismo ${ }^{163}$ expuesto, y su efecto acumulado y derivado en la estructura del sistema y su afectación a la competitividad.

\section{d. Resultado de la bistoria en la competitividad}

Una vez examinada la evolución del sistema tributario colombiano desde un enfoque jurídico y económico, es posible determinar que su estructuración tiene una marcada deficiencia de planeación, de proyección y de estabilidad jurídica, deficiencias que se han perpetuado en el tiempo y que se materializan en una evidente falta de competitividad en esta dimensión.

Es posible establecer en este punto que el sistema tributario colombiano es incrementalista, toda vez que resulta ser una herramienta de inmediatez y no el resultado de un proceso articulado de política pública, en razón a que la mayoría de los casos la justificación principal de modificación del sistema tributario obedeció a un desbalance fiscal por defecto de ingresos o por aumento del gasto, sin consideraciones sobre los efectos de

162 TABla 2. Aumento del Gasto del SECTOR Público (CiFras OFiCiales)

\begin{tabular}{|c|c|c|}
\hline Año & Gasto (Miles de Millones) & Variación porcentual \\
\hline 2005 & $99.724,3$ & 0 \\
\hline 2006 & $119.000,1$ & $19.32 \%$ \\
\hline 2007 & $136.607,6$ & $14.79 \%$ \\
\hline 2008 & $130.502,3$ & $-4.46 \%$ \\
\hline 2009 & $151.124,0$ & $15.80 \%$ \\
\hline 2010 & $163.847,1$ & $8.41 \%$ \\
\hline 2011 & $182.548,1$ & $11.41 \%$ \\
\hline 2012 & $190.809,2$ & $4.52 \%$ \\
\hline 2013 & $213.512,2$ & $11.89 \%$ \\
\hline 2014 & $236.988,3$ & $10.97 \%$ \\
\hline
\end{tabular}

Fuente: Elaboración propia, basado en Series estadísticas del Banco de la República de Colombia (BANREP).

163 Dentro del campo de políticas públicas, la escuela del incrementalismo surge como una aproximación descriptiva, ya que se edifica a partir de la comprobación empírica observada sobre los formuladores de política pública, donde a grandes rasgos se puede concluir que es la coyuntura y no el análisis racional (cuantitativo y cualitativo) lo que marca el derrotero del diseño, creación e implementación de una política pública; esta corriente de actuación no responde a un social óptimo ni esquematizado. Este enfoque reconoce contextos mecanismos desarticulados y mutables, por lo que a partir de la prueba y error, busca identificar las mejores opciones para el momento y periodo del problema público que se busca conjurar. 
equidad que se pudiesen generar, lo cual permite explicar el gran auge de la tributación indirecta (de naturaleza más regresiva pero de más difícil evasión) en Colombia en los últimos 50 años, o el aumento desmedido de las tasas efectivas de tributación de las empresas.

Diversos estudios han analizado en conjunto este tema arrojando los siguientes resultados

TABLA 4

\begin{tabular}{|c|c|}
\hline Fuente - Estudio & Tasa Efectiva de Tributación (TET) \\
\hline Fedesarrollo ${ }^{164}$ & $\begin{array}{l}\text { La TET promedio en Colombia se encontraría para el año } 2014 \text { / } \\
2015 \text { entre } 52,2 \% \text { y } 59,6 \%{ }^{165} \text {. }\end{array}$ \\
\hline Paying Taxes 2017 Y 2014 ${ }^{[166]}$ & $\begin{array}{l}\text { La TET promedio en Colombia se encontraría para el año } 2014 \text { / } \\
2016 \text { en el } 72 \% \text {. }\end{array}$ \\
\hline ANDI $^{167}$ & $\begin{array}{l}\text { La TET promedio en Colombia se encontraría para el año 2014/ } \\
2015 \text { en el } 68,1 \% \text {. }\end{array}$ \\
\hline Banco Mundial ${ }^{168}$ & $\begin{array}{l}\text { La TET promedio en Colombia se encontraría para los años 2011/ } \\
2015 \text { en el } 69,7 \% \text {. }\end{array}$ \\
\hline Comisión Legal de expertos & $\begin{array}{l}\text { La TET promedio en Colombia se encontraría para los años } 2014 \text { - } \\
2015 \text { entre el } 49 \% \text { y el } 105 \%{ }^{169} \text {. }\end{array}$ \\
\hline
\end{tabular}

164 Steiner, Roberto $;$ GÓmeZ, Hernando José, La Reforma Tributaria y su impacto sobre la Tasa Efectiva de Tributación de las firmas en Colombia, Coyuntura Económica: Investigación Económica y Social, Fedesarrollo, 2015.

165 La variación en la TET se debe al tamaño de la empresa, en razón a que después de un estudio contable, los autores del estudio concluyeron que las empresas pequeñas y grandes tenían tasas efectivas de tributación menores que las empresas medianas, en razón a que a medida que el tamaño de la empresa va creciendo, su función de producción va cambiando también. "Por un lado se encuentran las firmas grandes, dichas firmas son proporcionalmente más intensivas en el uso del capital, por el otro, están las firmas pequeñas, las cuales recurren a una mayor intensidad en la utilización de la mano de obra. En el medio de ambas se encuentran las empresas medianas, estas empresas consumen mucho más capital que las pequeñas, pero no el suficiente para gozar de las economías de escala y la mecanización, en consecuencia, el número de trabajadores contratados es proporcionalmente mayor al de las empresas grandes. Estos factores combinados, hacen que las empresas medianas paguen proporcionalmente más contribuciones sociales que las empresas grandes, y mayores impuestos al capital (como el patrimonio o predial) que las empresas pequeñas, lo cual repercute en unas tarifas efectivas de tributación mucho mayores".

166 Paying Taxes 2014: The global picture, Doing Business, Word Bank and PriceWater House Coopers "El informe Paying Taxes 2014, elaborado conjuntamente por PwC Tax \& Legal Services y El Banco Mundial, ofrece un profundo análisis de las principales tendencias en materia de fiscalidad internacional así como sobre los regímenes tributarios de 189 países en todo el mundo"

167 Encuesta tasa tributaria efectiva 2014: ¿cuánto pagan las empresas colombianas en impuestos?, Asociación de Industriales de Colombia (ANDI), documento preparado para servir como fuente de información en el trámite de la reforma tributaria de 2014 en Colombia, publicación electrónica, Bogotá, Colombia, 2014.

$168 \mathrm{http}: / /$ datos.bancomundial.org/indicador/IC.TAX.TOTL.CP.ZS.

169 Comisión de Expertos para la Equidad y la Competitividad Tributaria: "Lo que resulta común bajo las dos metodologías es la elevada dispersión de las tarifas efectivas promedio entre sectores (Cuadro 11). De acuerdo con el primer cálculo las tasas efectivas promedio oscilarían entre $49 \%$ y 105\%. Las tasas 
Así las cosas, opinar si una carga tributaria es alta o no resulta ser irrelevante, toda vez que no deja de ser una mera expresión subjetiva de cada ser en su consideración sobre el estado ideal de la tributación. Lo que sí resulta objetivo, contrastable e interesante medir, bajo un criterio de competitividad, es saber en grado comparado cómo se encuentra la TET respecto del mundo, o respecto de aquellos países con mercados competidores. En este entender, resulta interesante analizar que la tasa efectiva de tributación colombiana se encuentre en promedio 24 puntos porcentuales por encima de la tasa efectiva de tributación media del mundo ${ }^{170}$.

Todo lo anterior se puede ver reflejado en el bajo nivel de competitividad de nuestro sistema tributario, producto de la medición.

Los numerosos cambios a los que se ha enfrentado la legislación tributaria colombiana convierten al país en uno de los países con mayor variabilidad en las reglas tributarias. Dicha variabilidad ha tenido efectos considerables en la economía. Una encuesta realizada por The Global Competitiveness Report 2016-2017, que busca identificar problemas que dificultan realizar negocios en cada país, concluyó que 2 de las 3 principales causas que dificultan hacer negocios en Colombia corresponden a aspectos directamente relacionados con la tasa efectiva de tributación y con la regulación tributaria del país.

Lo anterior revela la deficiencia estructural del sistema tributario colombiano, haciéndose palmaria la preferencia continuada en el tiempo de preferir cambios marginales, antes que reformas estructurales, lo que ha afectado negativamente la calidad de la estructura tributaria de Colombia y la ha sumergido en un bucle regulatorio de reformas constantes, parcializadas e incrementales (acumulativas) ${ }^{171}$.

La deficiencia expuesta obedece a decisiones sobre el margen de la administración pública sobre sus posibilidades en el corto plazo para conjurar diversas coyunturas, que, como se vio, principalmente son de orden económico, en vez de tender a la búsqueda de un diseño óptimo y competitivo de la tributación, como la competitividad lo requiere.

Finalmente, se considera como otro punto a tener en cuenta la perdida de eficiencia y equidad que ha generado un descenso de la competitividad del sistema tributario co-

son elevadas porque solo se tienen en cuenta las empresas que declaran y tributan y se supone que no evaden. Indican que las empresas que no evaden en cada sector pagan tasas sumamente altas y con una dispersión considerable entre sectores (ya que los privilegios tributarios benefician más a unos sectores que a otros). De acuerdo con el segundo cálculo, las tasas efectivas oscilan entre $5.5 \%$ y $43 \%$. Este segundo cálculo muestra que hay sectores donde (además del efecto de los privilegios tributarios) la evasión y sub-declaración de utilidades es rampante y, por tanto, para los cuales la tasa efectiva promedio es bajísima". - informe final presentado al Ministro de Hacienda y Crédito Público, año 2015.

170 Paying Taxes 2017, Word Bank and PriceWater House Coopers "On average around the world in 2015, our case study company paid taxes amounting to $40.6 \%$ of its commercial profits".

171 Colombia cuenta con un sistema dual entre tributos nacionales y territoriales representado en $8 \mathrm{im}$ puestos nacionales principales y 3 territoriales principales y en promedio más alrededor de 13 tributos departamentales, 20 municipales y por lo menos 24 gravámenes y contribuciones, lo que genera un marco de normas bastante amplio que, aunque tiene efectos sobre la multiplicidad de impuestos, es claro que tiene un coste intrínseco de certeza jurídica y practicidad a la hora de cumplir con las obligaciones tributarias. 
lombiano fruto de la inestabilidad evidenciada a lo largo de los años. Esta inestabilidad jurídica y de reglas trasparentes en la fiscalidad ha afectado negativamente los mercados y el mismo sistema, generando efectos adversos sobre las decisiones de los agentes locales y externos, en cuanto al consumo, la inversión ${ }^{172}$, en la asignación eficiente de recursos en los mercados ${ }^{173}$; de igual forma, ha afectado la estructura general del sistema, tornándolo complejo ${ }^{174}$, fácil de evadir ${ }^{175}$ y con un coste elevado de administración y un régimen sancionatorio muy débil, lo cual ha generado el incentivo incorrecto de evasión en la sociedad en general, todo ello debido a la falta de planeación y a la intensiva frecuencia en el cambio de las normas ${ }^{176}$.

172 Lubos Pástor \& Pietro Veronesi, Political Uncertainty and Risk Premia, University of Chicago Booth School of Business, año 2011. Obtenido en: https://poseidon01.ssrn.com/delivery.php?ID = 75006608310106910706706809211709707600705601002306104902308500 710809510900612700411104111910710710804303709209211812510911909506008600800 806112302908411208800302107808608401708406501208608302400609112612207601200 $3006068088117083003124027025100001 \& \mathrm{EXT}=\mathrm{pdf}$

173 Baker, Scott R.; Bloom, Nicholas \& Davis, Steven J., Measuring Economic Policy Uncertainty, Working Paper 21633, National Bureau of Economic Research, 2015. Obtenido en: http://www.policyuncertainty.com/media/BakerBloomDavis.pdf

174 Paying Taxes 2017: Word Bank and PriceWater House Coopers. 2017. Siguiendo las mediciones realizadas por este estudio, es posible apreciar que el sistema tributario colombiano, dada su estructura, resulta complejo de cumplir. El indicador de esta afirmación se basa en el número de horas que les toma a los contribuyente en promedio cumplir con las obligaciones fiscales, así:

Tabla 3

\begin{tabular}{|l|c|c|}
\hline $\begin{array}{c}\text { Región / } \\
\text { País }\end{array}$ & $\begin{array}{c}\text { Número de Horas para cumplir } \\
\text { con las obligaciones tributarias }\end{array}$ & $\begin{array}{c}\text { Número de pagos tributarios } \\
\text { (promedio) }\end{array}$ \\
\hline Colombia & 239 & 12 \\
\hline África & 307 & 36,7 \\
\hline Asia & 212 & 23,5 \\
\hline EE.UU. & 197 & 8,2 \\
\hline EE/EFTA & 164 & 11,8 \\
\hline
\end{tabular}

Fuente: Elaboración propia.

175 Comisión de Expertos para la Equidad y la Competitividad Tributaria: "Los cálculos indican que cada punto de reducción de la tasa de evasión del impuesto de renta de las personas jurídicas le aportaría a los ingresos tributarios $\$ 442$ mil millones en pesos de $2012^{\prime \prime}$ - informe final presentado al Ministro de Hacienda y Crédito Público, 2015.

176 Aproximadamente en un periodo de 100 años como el estudiado en la presente investigación podemos hablar de un poco más de 51 reformas al sistema tributario colombiano. Se advierte que para el presente análisis solo se tuvieron en cuenta las reformas, que a juicio personal, resultaban ser principales. Lo cual me permite indicar que en Colombia en promedio se realizan 0,51 reformas tributarias por año, lo que equivaldría a establecer que se hace una reforma tributaria en Colombia cada 24 meses, aproximadamente. 


\section{BIBLIOGRAFÍA}

\section{Doctrina}

Asociación de Industriales de Colombia (ANDI) (2014). Encuesta tasa tributaria efectiva 2014: ¿cuánto pagan las empresas colombianas en impuestos?, documento preparado para servir como fuente de información en el trámite de la reforma tributaria de 2014 en Colombia, publicación electrónica, Bogotá, 2014.

BERNAL PINTO, JOSÉ JOAQUín (2012). "Los orígenes del impuesto directo y progresivo en América Latina". Historia y Sociedad, 2012.

Bravo, Carlos (2000). "El pensamiento económico de Jeremy Bentham". Revista Ciencias Humanas. UTP.

Cárdenas, Mauricio; Perry, Guillermo (1986). Diez años de reformas tributarias, Bogotá. Cid Fedesarrollo.

Comisión de Expertos para la Equidad y la Competitividad Tributaria (2015). Informe final presentado al Ministro de Hacienda y Crédito Público.

Consejo Privado de Competitividad (2017). Índice Nacional de Competitividad 2016-2017.

Departamento Nacional de Planeación (2012). Las reformas tributarias en el Siglo XX. Colombia. Giro Editores.

Duverger, Maurice (1968). Hacienda Pública, Barcelona, Bosch.

Escuela Superior de Administración Pública, ESAP (1961-62). La reforma Tributaria de 1960.

Junguito, Roberto; Rincón, Hernán (2004). "La Política Fiscal en el Siglo XX en Colombia", documento preparado para el seminario "Investigaciones recientes sobre historia económica colombiana". Disponible en https://core.ac.uk/download/files/153/7077619.pdf

LEWIN, AlFREDO (2008). "Historia de las reformas tributarias en Colombia", en autores varios Fundamentos de la Tributación, Universidad de los Andes, Editorial Temis.

Lubos, PÁstor \& Veronesi Pietro (2011). Political Uncertainty and Risk Premia, University of Chicago Booth School of Business. Obtenido en: https://poseidon01.ssrn.com/delivery. php?ID =75006608310106910706706809211709707600705601002306104902308500710 8095109006127004111041119107107108043037092092118125109119095060086008008 0611230290841120880030210780860840170840650120860830240060911261220760120 $03006068088117083003124027025100001 \&$ EXT $=$ pdf

Ministerio de Hacienda y Crédito Público, Marco Fiscal de Mediano Plazo del año 2009.

Ministerio de Hacienda y Crédito Público, Marco Fiscal de Mediano Plazo del año 2010.

Ministerio de Hacienda y Crédito Público, Marco Fiscal de Mediano Plazo del año 2011.

Ministerio de Hacienda y Crédito Público, Marco Fiscal de Mediano Plazo del año 2014.

Paying Taxes 2014: The global picture, Doing Business, Word Bank and PriceWater House Coopers "El informe Paying Taxes 2014".

Paying Taxes 2017: Word Bank and PriceWater House Coopers (2017). Disponible en: https:// www.pwc.com/gx/en/paying-taxes/pdf/pwc-paying-taxes-2017.pdf

PerRY, Guillermo (2010). Impuestos Nacionales y Locales, Hacia una reforma tributaria estructural, Colombia 2010-2014: propuestas de política pública. Corporación Andina de Fomento - Fedesarrollo. 
PInTO BeRnal, José JoAQuín (2012). Las Finanzas de la Gran Colombia, Instituto de Estudios Latino Americanos, Universidad de Alcalá.

Pormelau, Kyle; Cole, Alan, International Tax Competitiveness Index, Tax Foundation, 2015. Disponible en: http://taxfoundation.org/sites/default/files/docs/TF_ITCI_2015.pdf

Restrepo, Juan Camilo (2003). Hacienda Pública, Universidad Externado de Colombia, 2003.

Steiner, Roberto; GÓmeZ, Hernando José (2015). "La Reforma Tributaria y su impacto sobre la Tasa Efectiva de Tributación de las firmas en Colombia", Coyuntura Económica: Investigación Económica y Social, Fedesarrollo.

RODRíGUEZ, ÓSCAR (1996). "Nuevas Perspectivas en Historiografía Fiscal", Cuadernos de Economía, V. XV n. ${ }^{\circ} 24$.

Baker, Scott R.; Bloom, Nicholas \& Davis, Steven J. (2015). "Measuring Economic Policy Uncertainty", Working Paper 21633, National Bureau of Economic Research. Obtenido en http://www.policyuncertainty.com/media/BakerBloomDavis.pdf

Stiglitz, Joseph (2003). La Economía del Sector Público, Antoni Bosch, 3. a ed.

\section{Legal}

Constitución Política de 1991.

Ley 64 de 1927.

Ley 64 de 1927.

Ley 78 de 1935.

Ley 21 de 1963.

Ley 9 de 1983.

Ley 48 de 1983.

Ley 75 de 1986.

Ley 49 de 1990.

Ley 6 de 1992.

Ley 223 de 1995.

Ley 617 de 2000.

Ley 788 de 2002.

Ley 819 de 2003.

Ley 863 de 2003.

Ley 1111 de 2006.

Ley 1430 de 2010.

Ley 1607 de 2012.

Ley 1739 de 2014.

Ley 1819 de 2016.

Decreto 2331 de 1998. 